\title{
Visual Responses in the Lateral Geniculate Nucleus of Dichromatic and Trichromatic Marmosets (Callithrix jacchus)
}

\author{
Tsaiyao Yeh, ${ }^{1}$ Barry B. Lee, ${ }^{1}$ Jan Kremers, ${ }^{2}$ Jill A. Cowing, ${ }^{3}$ David M. Hunt, ${ }^{3}$ Paul R. Martin, ${ }^{4}$ and \\ John B. Troy ${ }^{5}$ \\ 1Department of Neurobiology, Max Planck Institute for Biophysical Chemistry, 37077 Göttingen, Germany, \\ 2Department of Experimental Ophthalmology, University of Tübingen Eye Hospital, Tübingen, Germany, \\ ${ }^{3}$ Department of Molecular Genetics, Institute of Ophthalmology, University of London, United Kingdom, ${ }^{4}$ Department \\ of Physiology F13, University of Sydney 2006, Australia, and ${ }^{5}$ Department of Biomedical Engineering, Northwestern \\ University, Evanston, Illinois 60201
}

\begin{abstract}
New-world primates such as the marmoset (Callithrix jacchus) show polymorphism for the middle- to long-wavelength sensitive cone pigments. Each X-chromosome carries a gene for only one of three possible pigments. All males are thus dichromats, but some females will be trichromats. We have investigated the responses of cells of the parvocellular (PC) and magnocellular (MC) systems within animals from a single marmoset family. The middleto long-wavelength pigment of dichromats was identified physiologically. Trichromats could readily be distinguished from dichromats by the presence of a high proportion of red-green opponent PC-cells. The physiological classification of phenotypes was confirmed with genetic analysis. The pattern of inheritance was consistent with current genetic models. In trichromatic females, the properties of cells resembled in detail those of cells from the PC- and MC-pathways of the macaque. In dichromats, cell responses resembled those of trichromats (except for the lack of opponency in PC-cells); PC-cells showed sustained and MC-cells transient responses, with a lower contrast gain for the former type. One difference was that a proportion of PC-cells in dichromats showed strong rod input even at high levels of retinal illuminance. Thus, in trichromatic marmosets the presence of two middle- to long-wave pigments appears to permit the elaboration of all the physiological properties associated with trichromacy.
\end{abstract}

[Key words: magnocellular pathway, parvocellular pathway, new-world primate, marmoset, color vision, dichromat, trichromat]

Anatomically, the afferent visual pathway of the new-world primate resembles that of its old-world relatives. Retinal anatomy appears superficially similar in the two families (Stone and Johnstone, 1981; Leventhal et al., 1989; Ghosh et al., 1994; Martin et al., 1995). The lateral geniculate nucleus (LGN) is divided

\footnotetext{
Received Mar. 28, 1995; revised July 10, 1995; accepted July 14, 1995.

We thank James Bowmaker for making his marmoset cone spectra available to us. This work was partially supported by DFG Grant II B 7 Le 524/8-1 to B.B.L. J.A.C. and D.M.H. were supported by the UK Medical Research Council and the Wellcome Trust. P.R.M. was supported by Australian NHMRC Grant 0931101 . JBT was supported by NIH EY06669. Travel expenses of J.B.T. and B.B.L. were supported by NATO Collaborative Research Grant 931162

Correspondence should be addressed to Barry B. Lee at the above address.

Copyright $\odot 1995$ Society for Neuroscience $0270-6474 / 95 / 157892-13 \$ 05.00 / 0$
}

into magnocellular (MC) and parvocellular (PC) layers, within which each eye has separate projections, although the lamination pattern is less apparent and more variable than in macaques (Doty et al., 1966; Wong-Riley, 1972; Spatz, 1978). Physiologically, cells of the magnocellular (MC) pathway deliver transient and those of the parvocellular (PC) pathway sustained responses (Sherman et al., 1976), as in old-world species. However, behavioral and genetic analysis (Jacobs, 1984; Jacobs and Neitz, 1985; Jacobs et al., 1987; Williams et al., 1992; Hunt et al., 1993; Jacobs et al., 1993) has recently shown that inheritance of visual pigments is quite different in the two families. There is only one gene coding for a pigment sensitive in the middleto-long (M-L) wavelength region on the X-chromosome of newworld primates, so that all males are dichromats. Females enjoy trichromatic vision if each of their X-chromosomes codes for a different pigment. Three alleles of the $\mathrm{M}-\mathrm{L}$ pigment have been identified in almost every new-world species so far studied (Jacobs et al., 1993). As in other species, the short-wavelength (S) pigment gene is autosomal.

Early attempts to identify the proportion of color-selective cells in the new-world primate LGN yielded a relatively small proportion of cells (ca. 15\%) with obvious cone opponency (Jacobs and DeValois, 1965). At that time, the existence of dichromatic animals in the population was not suspected, although retrospective analysis later showed a much higher proportion of color-opponent neurons in female animals (Jacobs, 1983). In view of the recent behavioral and genetic evidence, we have compared the properties of PC- and MC-pathways in dichromatic and trichromatic representatives of a new-world primate species, the common marmoset. Two comparisons were of interest. Similarities between PC- and MC-pathways in trichromatic animals with those of an old-world primate, the macaque, Inay indicate if these cell systems share common features throughout the primate order. Secondly, a comparison of the pathways in dichromatic and trichromatic marmosets may yield information as to how these pathways might be modified by the presence or absence of a second $\mathrm{M}-\mathrm{L}$ pigment. In particular, we wished to ascertain if the PC-pathway in dichromats was like a "color-blind" version of that in trichromats, or resembled more the sustained cells seen in other mammals such as the cat. We have concentrated in these experiments on the chromatic and temporal properties of these neurons; the spatial properties of their receptive fields remain to be investigated. 
Some of these results have been presented in abstract form (Yeh et al., 1994; Martin et al., 1995).

\section{Materials and Methods}

Physiological measurements. Marmosets (C. jacchus) were from a breeding colony in the Max Planck Institute for Biophysical Chemistry, Göttingen. Most animals derived from a single family. Animals were anesthetized initially with an intramuscular injection of ketamine (ca. $20 \mathrm{mg} / \mathrm{kg}$ ), following premedication with chlorpromazine (ca. $10 \mathrm{mg} /$ $\mathrm{kg}$ ). In some experiments, anesthesia was then maintained with isofluorane (1-2\% during surgical procedures, $0.2-1 \%$ during recording) in a $70 \% / 30 \% \mathrm{~N}_{2} \mathrm{O} / \mathrm{O}$, mixture. In later experiments, anesthesia was maintained by intravenous infusion of sufentanyl ( $1-4 \mu \mathrm{g}$ per $\mathrm{kg}$ per hour). EEG and the electrocardiogram were carefully monitored as a control for depth of anesthesia. Muscular relaxation was achieved by intravenous infusion of gallamine triethiodide $(5 \mathrm{mg} / \mathrm{kg} / \mathrm{hr})$ together with $1 \mathrm{ml} /$ $\mathrm{hr}$ of dextrose Ringer's solution. Antibiotic and corticosteroids were administered intramuscularly. End-tidal $\mathrm{pCO}_{2}$ was checked periodically and kept near $4 \%$ by adjusting the rate and depth of ventilation, and/or by admixture of $\mathrm{CO}_{2}$ to the inspired gases. Rectal temperature was maintained near $37.5^{\circ} \mathrm{C}$. The animal was mounted in a stereotaxic frame.

The eyes were protected by oxygen-permeable contact lenses and focused on a tangent screen $1.14 \mathrm{~m}$ from the animal. Retinal landmarks were back-projected onto the screen. Their geometry resembled that of the old-world primate. After muscle relaxation, the optic axes make an angle of $20^{\circ}$ downward relative to the coronal stereotaxic plane, and the stereotaxic frame was tilted to make the axes horizontal.

Recordings were obtained from the LGN or, on a few occasions, from the optic tract. Tungsten-in-glass electrodes were lowered into the target structure through a small craniotomy, which was then sealed. The retinotopic map of the macaque LGN (Malpeli and Baker, 1975) proved a reasonable guide to retinotopy within the LGN of the marmoset. Receptive fields were plotted on the tangent screen with flashed spots of different colors. Recordings from the parvocellular laminae were distinguished by low contrast sensitivity and sustained responses relative to the magnocellular layers, even in dichromatic animals. Electrolytic lesions were made close to the border between parvocellular and magnocellular laminae to permit later verification of recording sites.

Stimuli were presented through a Maxwellian view system with red, green, and blue diodes (LEDs) as light sources (modified from Swanson et al. (1987)). The aerial image of the LEDs was ca. $3 \mathrm{~mm}$ in diameter and was centered in the pupil. The system could be rotated about the pupil so as to center the stimulus on a cell's receptive field. The temporal waveforms for the LEDs were generated by a computer through 12 bit digital-to-analog converters. The LEDs were driven by means of a frequency-modulated pulse train which provided a highly linear relationship between driving voltage and light output. The spectral energy distribution of the LEDs was measured using a spectroradiometer (model pro-703/PC, Photo Research, Burbank, CA). The dominant wavelengths of the LEDs were 638,554 , and $470 \mathrm{~nm}$. The blue LED was used mainly for testing blue-on cells. For other neurons, the red and green LEDs alone were used and calculations for the subsequent analysis were done only for these LEDs. In the standard condition, the relative luminances of the LEDs for a human observer were set equal by heterochromatic flicker photometry by an observer whose luminosity function matched that of the $2^{\circ}$ Judd (1951) observer. Mean chromaticity was then $595 \mathrm{~nm}$. Retinal illuminance levels were estimated as described by Westheimer (1966). For the red and green LEDs together, it was ca. $2000 \mathrm{td}$ but because of the smaller marmoset eye (Troilo et al., 1993), the retinal flux per troland is about four times that in humans. Not knowing how the size of the marmoset's pupil depends on retinal illuminance in the wild, we were concerned that the unattenuated LEDs provided a retinal illuminance greater than normally encountered by these animals. For this reason, stimuli were usually attenuated with a 1ND filter.

Three sets of measurements were usually made on each cell: we recorded responses to pulse stimuli, responses on changing the relative phase of the red and green LEDs, and responses to luminance and/or chromatic modulation as a function of temporal frequency and contrast. (1) Responses to $200 \mathrm{msec}$ pulses were measured to assess the time course of responses. Pulses were incremental or decremental luminance pulses, or redward or greenward chromatic perturbations away from the mean chromaticity. In the former case the red and green LEDs were driven in phase, in the latter out of phase. (2) To further assess cells' spectral sensitivity and search for signs of cone opponency, we measured responses to sinusoids at a variety of relative red and green diode phases (Smith et al., 1992). With this stimulus, the relative phase of the red and green lights is manipulated with their modulation depths being held constant. Responses were measured at 16 relative phases at intervals of $22.5^{\circ}$ at six temporal frequencies. The red LED modulation was taken as a reference, and diode phases described in the text refer to the phase of the green relative to the red LED. Diode modulation depth was usually set at $50 \%$, but was set at $20 \%$ if from response histograms saturation appeared to be occurring, or at $100 \%$ for some poorly responsive cells. A formal description of this stimulus can be found in Lindsey et al. (1986), and the way in which cell data can be modeled based on pigment spectra is described in detail by Smith et al. (1992). The pigment spectral sensitivities used were derived from microspectrophotometry and corrected for marmoset preretinal absorption (J. M. Bowmaker, personal communication). From the LED spectra, marmoset pigment absorption spectra and the human luminosity calibration we calculated the absorption in each pigment for each stimulus condition, absorption spectra of the pigments being normalized to a maximum value of unity. For dichromatic animals, the dependence of response phase on relative red and green LED phase for each pigment could be predicted. As a further check, data were also collected after increasing or decreasing the mean level of the red LED, when characteristic changes of response phase are predicted. For trichromatic animals, the amplitude and phase data provided a direct indication of color opponency, and cone weightings were derived as in Smith et al. (1992). (3) Responsivity as a function of temporal frequency and contrast was measured, usually at seven to nine temporal frequencies from 0.61 up to 78 $\mathrm{Hz}$ (if the cell still responded), and at seven contrasts. Luminance modulation, with the LEDs in phase was employed for all cells, and for opponent cells responses to chromatic modulation, with the LEDs out of phasc, was also measurcd. For all sinusoidal modulation conditions, about $6 \mathrm{sec}$ of activity was averaged for each condition, and first and second harmonic amplitudes and phases extracted.

At the end of the experiment, the animal was killed with an overdose of barbiturate. A sample of liver tissue was removed for identification of the visual pigments. The brain was perfused with paraformaldehyde (4\%) and histologically processed for reconstruction of electrode tracks.

Genetic analysis. Excised liver was minced and suspended in absolute ethanol for approximately $30 \mathrm{~min}$. The ethanol was aspirated and replaced with a fresh solution for storage. After homogenization of the tissue in a buffer ( $25 \mathrm{~mm}$ EDTA pH $8.0,150 \mathrm{~mm}$ sodium chloride) and digestion with proteinase $\mathrm{K}(100 \mu \mathrm{g} / \mathrm{ml})$ and $10 \%$ sodium dodecyl sulfate $(10 \mu \mathrm{g} / \mathrm{ml})$, DNA was isolated using standard phenol/chloroform extraction.

The polymerase chain reaction (PCR) was used to amplify regions within exons 3 and 5 of the opsin gene using the following primer pairs: 5'-ATGACGGGTCTCTGGTCCCTG- ${ }^{\prime}$ and 5'-CTCCAACCAAAGATGGGCGG-3' for exon 3, and 5'-GAATTCCACCCAGAAGGCAGAG-3' and 5'-GTCGACGGGGTTGTAGTAGTGGC-3' for exon 5. Each reaction contained $1 \mathrm{U}$ of Taq polymerase; $200 \mathrm{ng}$ each of dATP, dCTP, dGTP, and dTTP; $200 \mathrm{ng}$ of the respective primers, and approximately $200 \mathrm{ng}$ of genomic DNA and a reaction buffer, in a total of $25 \mathrm{ml}$. The parameters used for PCR were: annealing at $56^{\circ} \mathrm{C}$ or $58^{\circ} \mathrm{C}$ (for exons 3 and 5 , respectively), elongation at $72^{\circ} \mathrm{C}$ and denaturation at $94^{\circ} \mathrm{C}$. Thirty cycles were performed.

Products were viewed after electrophoresis in a $1.5 \%$ low meltingpoint agarose gel with $0.5 \times$ Tris-acetate EDTA buffer $(0.02 \mathrm{M}$ Trisacetate, $0.5 \mathrm{mM}$ EDTA pH 8.0), by staining with a solution of ethidium bromide $(0.5 \mu \mathrm{g} / \mathrm{ml})$. It was important to ensure that a single, clear band was present.

The single-strand conformation polymorphism (SSCP) method used was based on that of Hongyo et al. (1993). Five microliters of PCR product (20-100 ng DNA), $0.4 \mu \mathrm{l}$ of $1 \mathrm{M}$ methylmercury II hydroxide (Johnson Matthey), 15\% ficoll loading buffer (containing $0.25 \%$ bromophenol blue and $0.25 \%$ xylene cylanol), and $13.6 \mathrm{ml}$ of $1 \times$ Trisborate EDTA buffer ( $90 \mathrm{~mm}$ Tris, $92 \mathrm{~mm}$ boric acid, $25 \mathrm{~mm}$ EDTA pH 8.0) were mixed, heated to $90^{\circ} \mathrm{C}$ for $5 \mathrm{~min}$ and plunged into ice prior to loading on to a polyacrylamide gradient gel.

Samples were loaded on to a $10-20 \%$ gradient polyacrylamide TBE gel (37.5:1 acrylamide to bis-acrylamide), run in $1.5 \times$ TBE buffer. A Stratagene Strata therm Cold power pack and temperature monitor were used to maintain the gel at a constant $12^{\circ} \mathrm{C}$ for approximately $16 \mathrm{hr}$ at $400 \mathrm{~V}$. Subsequent to electrophoresis, gels were stained in a $1: 10,000$ solution of CYBR green in $1.5 \times$ TBE (Molecular Probes Inc., OR) for 


\section{A Marmoset Family}

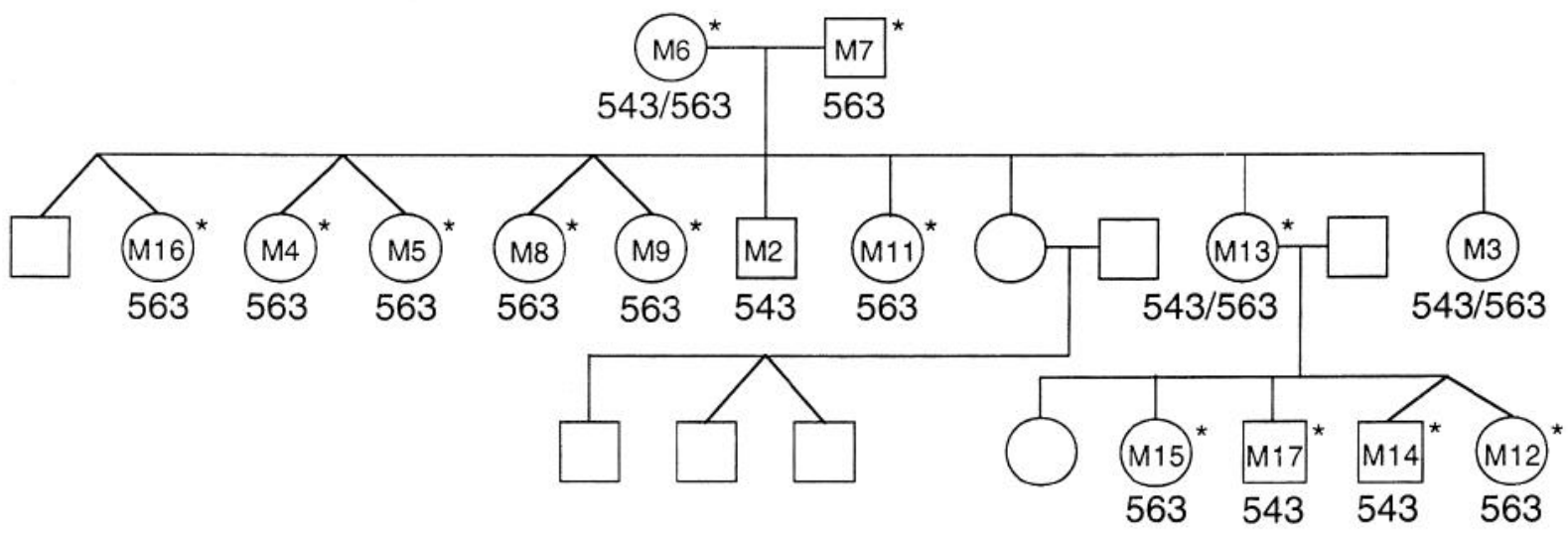

B

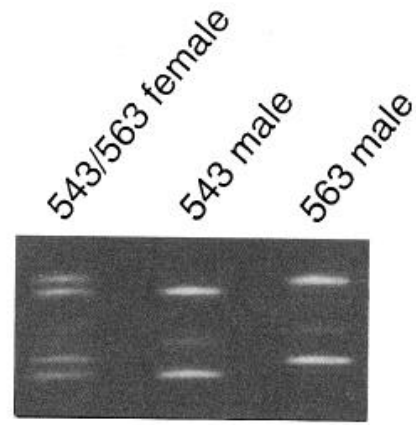

Figure 1. A, Pedigree of marmoset family investigated. Each animal (males, squares; females, circles) is identified by the peak wavelength of the visual pigment(s) carried, and by a number used for identification in later figures. Unidentified animals are surviving. All animals marked with an asterisk were subjected to genetic analysis by SSCP. In every case the genetic analysis confirmed the physiological classification. $B$, Examples of the band patterns of PCR-generated fragments from exon 5 of the opsin gene after SSCP analysis for a 543 and a $563 \mathrm{~nm}$ male and a $543 / 563 \mathrm{~nm}$ female.

approximately $30 \mathrm{~min}$. Epiillumination was used to view the gels which were then photographed through a yellow gelatine filter (Kodak).

\section{Results}

\section{Distribution of pigments within a marmoset family}

Figure $1 A$ shows the pedigree of 15 of the 16 animals studied. Next to each animal the peak wavelength $(543 \mathrm{and} / \mathrm{or} 563 \mathrm{~nm}$ ) for the identified M-L pigment(s) are indicated. In some females, red-green color opponency was immediately apparent on recording from the parvocellular layers. We assumed these animals to have been trichromats and they are shown with two pigments. In other females and all males, PC-cells were without cone opponency, and we assumed these animals to have been dichromats. For each animal, the phenotype was initially determined through the electrophysiological recordings, as described below. For all except the two animals without stars, liver samples were taken for genetic analysis by SSCP, a method that can identify single nucleotide differences between DNA fragments from their electrophoretic migration pattern after denaturation. The spectral difference between the 563 and 543 pigments is determined by two different amino acid substitutions arising from single basepair substitutions in exons 3 and 5, respectively, of the opsin gene (Williams et al., 1992), although the alleles that specify these pigments can be identified by reference to either exon. The migration of the denatured PCR-generated fragments from the exon 5 was used to determine the genotype of these animals
(Fig. $1 B$ ), and the accuracy of this method was confirmed with animals from a previous study where the absorbance maxima of the pigments had been determined by microspectrophometry (Williams et al., 1992). For all 563 and $543 \mathrm{~nm}$ animals, two strong bands were present, and the molecular difference between the fragments could be clearly seen as band shifts, whereas in heterozygous $563 / 543 \mathrm{~nm}$ females, four strong bands could be seen, corresponding to the 563 and $543 \mathrm{~nm}$ band pairs. In every case, the electrophysiological identification of the phenotype was confirmed. Below, we refer to animals as dichromats and trichromats based on this electrophysiological and genetic identification, but it should be remembered that these terms refer to a categorization of color vision rather than a definition derived from pigment count, genetics or electrophysiology. The numbers of each animal are used to identify the source of data in later figures.

Only the 543 and $563 \mathrm{~nm}$ pigments were present in the family. With a trichromatic female (M6) and a $563 \mathrm{~nm}$ male (M7) as parents, $50 \%$ of the daughters would be expected to be trichromats, but this was so for only two of the eight studied. The pattern in Figure 1 is consistent with the current model for inheritance of pigment genes in new-world primates (Tovee et al., 1992; Williams et al., 1992), although it should be noted that in the latter study one animal from one pedigree did show evidence for a pigment not expected from the model. 
A

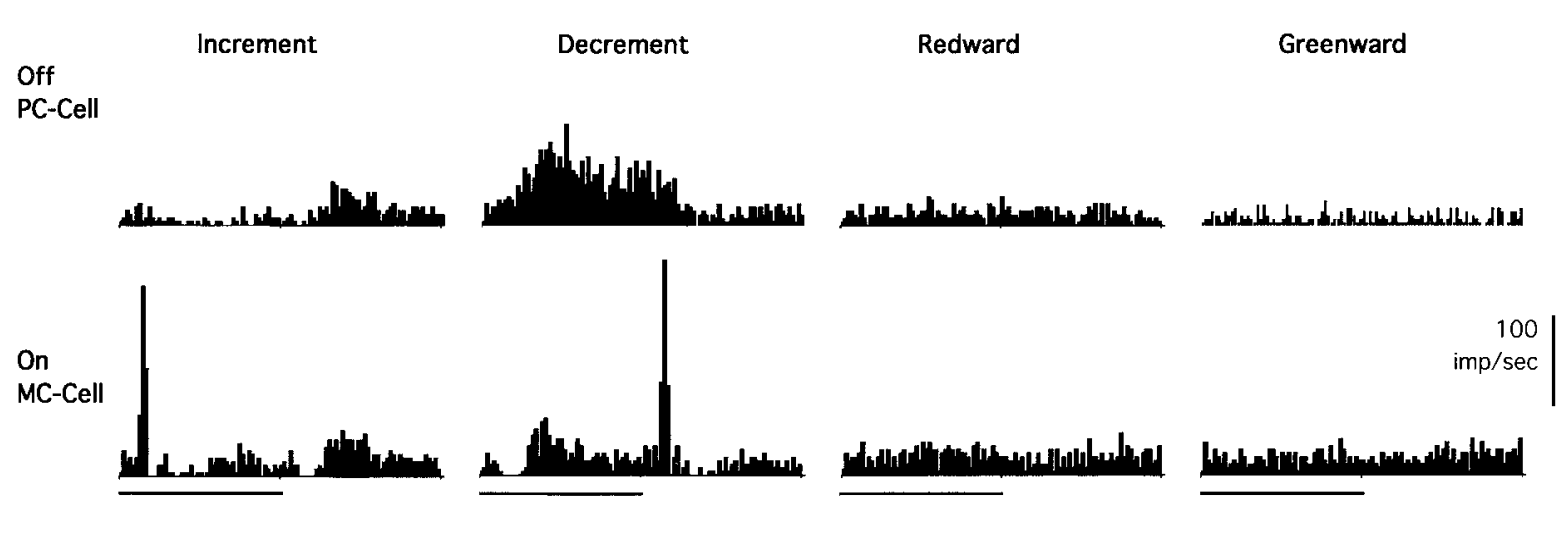

B

Male Dichromat, $563 \mathrm{~nm}(\mathrm{M7})$
Female Dichromat, 563 nm (M9)

Decrement Redward

sec

\section{On \\ PC-Cell}
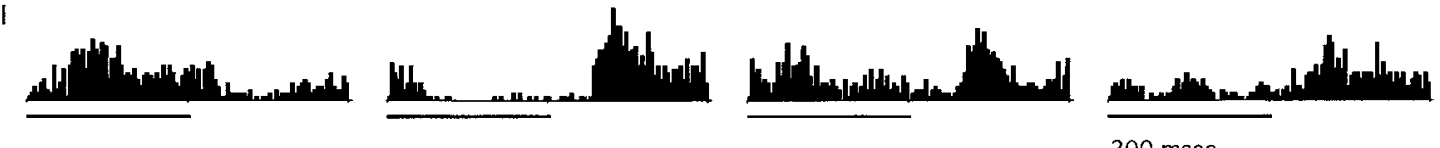

200 msec

Figure 2. A, Flash responses of an off PC cell and an on MC-cell from a dichromatic female (563 nm) to 200 msec luminance increments and decrements and redward and greenward perturbations. $\Delta I / I$ for luminance increments and decrements was 0.5 . For redward and greenward perturbations $\Delta I / I$ was also 0.5 in terms of diode modulation, with the diodes modulated out of phase. In terms of cone modulation, this results in a ca. 0.039 change for the $563 \mathrm{~nm}$ pigment. Cells show sustained and transient responses, respectively. $B$, Flash response to the same stimuli from a dichromatic male $(563 \mathrm{~nm})$. The cell gave an incremental luminance response but also gave a response to redward and greenward perturbations. Bars show $200 \mathrm{msec}$ stimulus duration; $6 \mathrm{msec} / \mathrm{bin}$, average of 40 presentations.

\section{Visual responses in dichromats and trichromats.}

On lowering an electrode into the LGN, the first recordings were obtained from the parvocellular laminae. Responses were usually sustained in both dichromatic and trichromatic animals. On passage of the electrode into the magnocellular laminae, cell responses became much more transient, and contrast sensitivity increased, as in the macaque (e.g., Kaplan and Shapley, 1982). With hand-held, flashed stimuli, trichromatic females could often be distinguished from dichromats by a degree of spectral selectivity in PC-cell responses, although this was sometimes not obvious. To reliably distinguish between dichromats and trichromats and to assess the strength and balance of receptor inputs, we measured response amplitude and phase on changing the relative phase of red and green heterochromatically modulated lights (Smith et al., 1992). With this stimulus, the red and green lights are sinusoidally modulated at a given frequency. The modulation depths are held constant, and their relative phase manipulated. Response amplitude and phase measured with this protocol gives a sensitive indication of the presence of cone opponency.

In both dichromats and trichromats, blue-on cells with shortwavelength ( $\mathrm{S}$ ) cone input were occasionally encountered (ca. $5-10 \%$ of recorded neurons), as in an earlier study (Jacobs, 1983). There was no obvious difference in encounter rate between dichromats and trichromats. Responses of blue-on cells were similar to those of these cells in macaques (e.g., Smith et al., 1992; Yeh et al., 1995) and will not be further discussed.

We measured responses of 180 cells from the parvocellular laminae and 36 cells from the magnocellular laminae. The position of the recorded cells was confirmed by subsequent histol- ogy. Retinal eccentricity ranged between $3^{\circ}$ and $20^{\circ}$. On several occasions pre- (S-) potentials were recorded and these were taken to represent activity of retinal ganglion cell afferents (Lee et al., 1983; Kaplan and Shapley, 1981). Cell activity often showed a bursting pattern towards the end of long experiments, similar to recordings in the cat when hyperpolarisation brings about calcium spikes (McCormick and Feeser, 1990). We then attempted to record from fibers in the optic tract, identifying cells on the basis of response pattern. Together with the prepotential recordings, this provided a control that the poor responsiveness in the parvocellular laminae of dichromats was not due to a high level of geniculate inhibition.

Each cell was tested with 200 msec luminance and chromatic pulses to give an indication of response time course and to test for obvious cone opponency. Figure $2 A$ shows responses from a PCand a MC-cell from a dichromatic $(563 \mathrm{~nm})$ female. Pulses were incremental or decremental luminance pulses, or redward or greenward chromatic perturbations. For luminance pulses, responses of the PC-cell are more sustained and have a longer rise time to peak than for the MC-cell. Chromatic perturbations evoked weaker or no responses, depending on the pigment present. The responses in Figure $2 A$ were typical of most cells encountered in dichromatic animals. However, a minority of PC-cells $(12 \%)$ showed unexpected behavior. An example is shown in Figure $2 B$. To a luminance increment, the cell shows a sustained on-response. However, the cell also gave a more transient response to redward or greenward pulses. Such cells were observed at all eccentricities and in both male and female dichromats. Data discussed in a subsequent section make it likely that such PC-cells receive input from rods as well as from the M-L cone. 
A

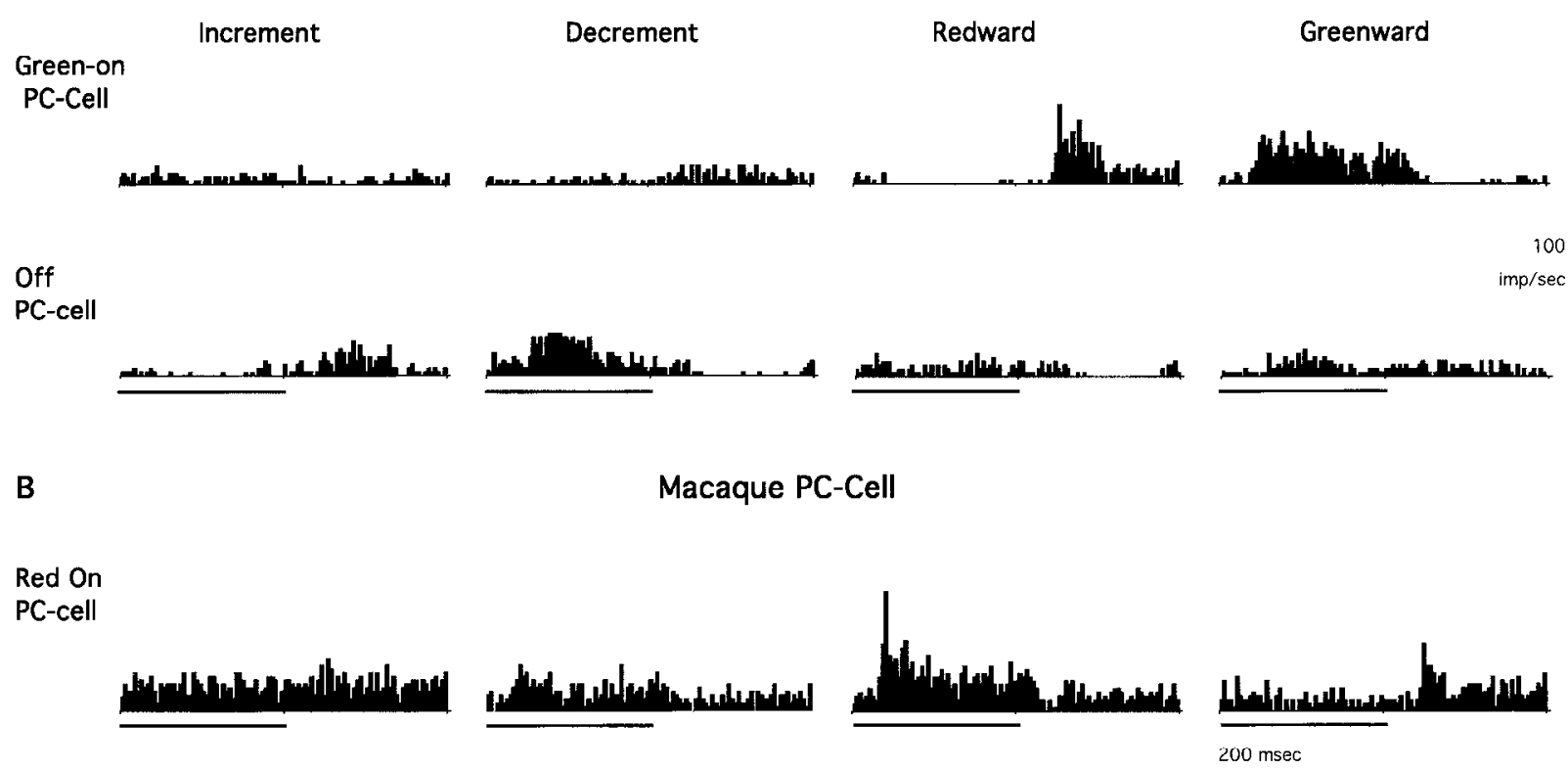

Figure 3. A Flash responses of a green on PC cell and an off PC-cell from a trichromatic female (543-563 nm) to $200 \mathrm{msec}$ luminance increments and decrements and redward and greenward perturbations as in Figure 2. The green on cell gives a sustained on-response to the greenward pulse and an off response to the redward pulse. The off cell gives no chromatic response. $B$, Response to the same stimuli from a macaque red-on cell. A sustained response to the redward pulse is seen. Bars show $200 \mathrm{msec}$ stimulus duration; $6 \mathrm{msec} / \mathrm{bin}$, average of 40 presentations.

Figure $3 A$ shows examples of PC-cells responses from a trichromatic animal. For the cell shown in the upper set of histograms, there is little or no response to luminance increments or decrements. To the chromatic perturbations, a decrease to the redward and an increase in firing to the greenward can be seen, and this response pattern indicates cone opponency. Most PC-cells in trichromats showed an indication of cone opponency with this stimulus, but exceptions were found. An example is shown in the lower set of histograms in Figure $3 A$. This cell gave an off-response to luminance stimuli and little response to the chromatic pulses. For comparison, Figure $3 B$ shows responses of a red-on ganglion cell from the retina of a macaque to the same stimulus. The cell fires in response to the redward perturbation but gives little or no response to the luminance stimuli.

Responses of PC- and MC-cells in both dichromatic and trichromatic marmosets thus showed sustained and transient responses respectively, as in old-world primates. In trichromats, responses to redward or greenward pulses were usually similar to those found in macaque red-green PC-cells. MC-cells in trichromats displayed transient, broad-band spectral sensitivity as in the macaque.

\section{Measurement of spectral sensitivity in dichromats}

The protocol in which the relative phase of the red and green diodes was varied was used to identify the $\mathrm{M}-\mathrm{L}$ pigment present in dichromats. A detailed description of the paradigm is given in Smith et al. (1992). Both the 543 and $563 \mathrm{~mm}$ pigments absorb light from both the red and the green LEDs. Both cones will show the greatest modulation amplitude when $\theta$, the relative phase of the green relative to the red LED, is zero. However, the $543 \mathrm{~nm}$ pigment absorbs preferentially from the green LED and the $563 \mathrm{~nm}$ pigment from the red LED. When relative diode phase is varied, response phase thus provides a signature by which the pigment can be identified. From the cone spectra of the $543 \mathrm{~nm}$ and $563 \mathrm{~nm}$ pigments (J. Bowmaker, personal communication) prediction of cone re- sponse amplitude and phase as a function of relative diode phase may be made for each of the three pigments using the equations

$$
P_{563 \mathrm{amp}}=\left(S_{563 G^{2}}+S_{563 \mathrm{R}}^{2}+2 S_{563 \mathrm{G}} S_{563 \mathrm{R}} \cos \theta\right)^{0.5}
$$

and

$$
P_{56,3 \text { phase }}=\arctan \left[S_{563 \mathrm{G}} \sin \theta /\left(S_{56,3 \mathrm{R}}+S_{563 \mathrm{G}} \cos \theta\right)\right] .
$$

These are obtained by vector combination of the $563 \mathrm{~nm}$ cone responses to the red and green lights and are taken from Smith et al., 1992 (their Eqs. 1 and 2). $P_{563 \text { anp }}$ and $P_{563 \text { phase }}$ are amplitudes and phase of the $563 \mathrm{~nm}$ pigment response to the green $\left(S_{563 \mathrm{G}}\right)$ and red $\left(S_{563 R}\right)$ lights as a function of $\theta$. Similar equations are written for the other two pigments. If it is assumed that the cell response is linearly related to the cone response, then Equations 1 and 2 can be used to predict cell behavior directly. Figure 4 shows the relationship between cell response phase and relative diode phase expected for each pigment, with the relative levels of the diodes set at a match according to the human $2^{\circ}$ luminosity function. Individual points represent phase values for which calculations were carricd out and at which measurements were performed.

The slope and shape of the relationship is dependent upon the pigment present. The red diode phase was used as the reference and so is constant. The $563 \mathrm{~nm}$ curve has a shallow slope because this pigment absorbs most light from the red diode. The $543 \mathrm{~nm}$ pigment absorbs most light from the green diode, and the relationship is steeper. The $557 \mathrm{~nm}$ curve follows an intermediate course. If the spectra of the pigments are known, this method of identifying the pigment present has advantages over a flicker photometric method. Fits of data to the theoretical curve are determined by a number of points where responses are vigorous rather than a single null value around which responses are weak. Secondly, response phase is often a more stable measure than response amplitude.

Figure 5 show amplitude and phase data for two on-center PCcells, one from a $543 \mathrm{~nm}$ male, the other from a $563 \mathrm{~nm}$ female dichromat. The upper panels show response amplitude as a function 
Using Phase to Identify Pigments

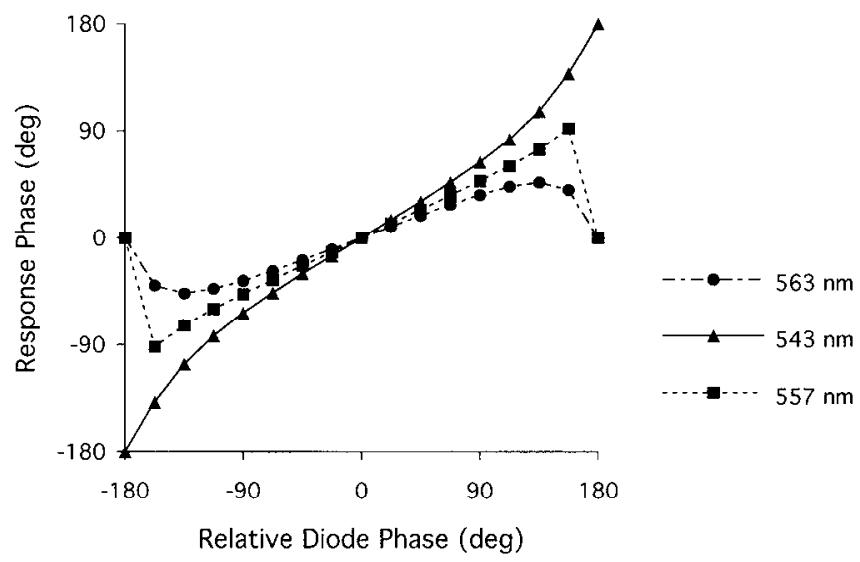

Figure 4. Theoretically derived phase templates for the three possible visual pigments. The phase of the green light was changed relative to the phase of the red light; $0^{\circ}$ represents in-phase modulation of the lights and $\pm 180^{\circ}$ counterphase modulation. Based on the cone spectra and allowing for preretinal absorption, response phase was predicted as a function of relative diode phase using Equation 2.

of relative diode phase and the lower panels show response phase. Response amplitude was maximal with the diodes in phase $\left(0^{\circ}\right)$ and minimal when in antiphase $\left(180^{\circ}\right)$. This is typical of a cell lacking opponency (Smith et al., 1992). The phase templates (Eq. 2) have been fitted to the data by translating them vertically, using a least squares criterion. A reasonable fit was achieved in each case. Some divergence between data and prediction can be seen in these and subsequent figures, usually for points where amplitude was low. However, these were never such as to call the pigment identification into question. Response amplitude data were fitted with Equation 1 using a single scaling parameter. Again a reasonable fit was achieved.

We performed two further tests of the validity of this analysis. In Figure 6 are shown amplitude and phase data from an off center MC-cell from a $563 \mathrm{~nm}$ dichromatic female, at three temporal frequencies $(1.22,19.5$, and $39.5 \mathrm{~Hz})$. If the shape of the phase relation is a reliable signature to identify a given cone pigment, then on changing temporal frequency response phase will change, but data should still be fittable with the same template by shifting its ordinate position. This can be seen to be the case in Figure 6, where the phase template was shifted on the ordinate to obtain the best least-squares fit for each frequency. The same amplitude template has been fitted to each set of amplitude data, using a single scaling parameter. Both the amplitude and phase fits capture most features of the data.

Figure 6 also demonstrates that phase data from MC-cells were similar to those from PC-cells in dichromatic animals with the same pigment, as can be seen by comparing the data from the $563 \mathrm{~nm}$ dichromat in Figure 5 with those in Figure 6. The transient response of the MC-cell results in a more vigorous response to $19.52 \mathrm{~Hz}$ than to $1.22 \mathrm{~Hz}$.

In a second test of the validity of the analysis, the mean level of the red diode was altered (keeping percentage modulation constant) and measurements repeated. The phase data change in shape. Amplitude and phase data for a PC-cell from a $543 \mathrm{~nm}$ dichromatic male are shown for three levels of the red LED in Figure 7. The left panel shows amplitude and phase data at the setting for the standard human observer (red $=$ green). The other panels show
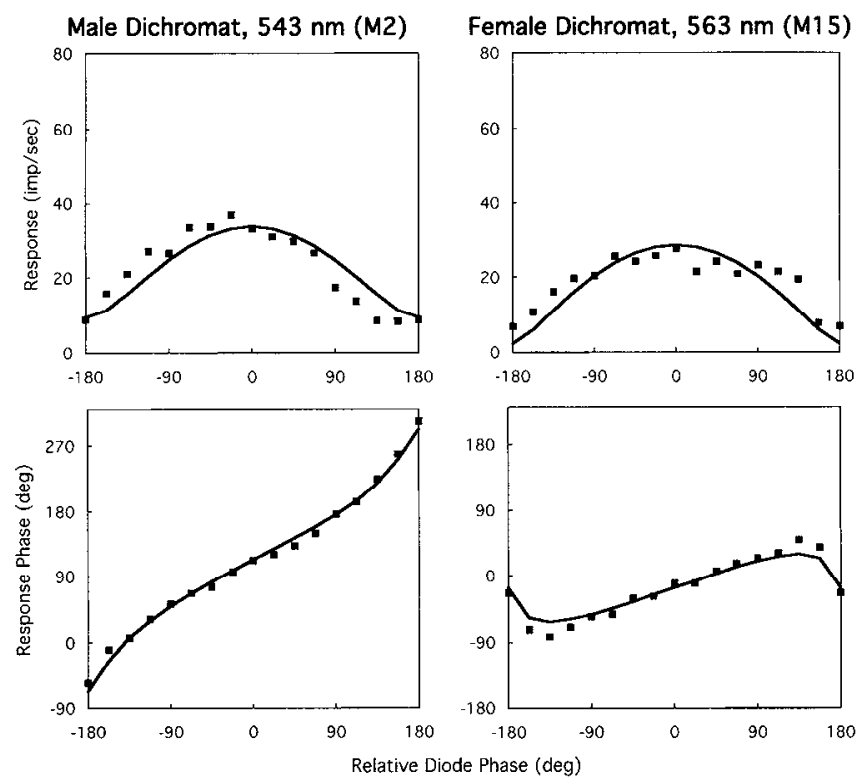

Figure 5. Responses of PC-cells from 543 (off cell) and $563 \mathrm{~nm}$ (on cell) dichromats on changing the relative phase of red and green Inodulated lights. The top panels show response amplitude as a function of relative diode phase. Both cells show a similar pattern. The bottom panels show response phase. Each set of phase data is characteristic for the pigment involved. Solid lines for the phase data show phase templates translated on the ordinate to obtain best least-squares fits as described in the text. Solid lines for amplitude data were fitted by scaling the amplitude template. Data were acquired with $50 \%$ diode modulation at $2.44 \mathrm{~Hz}$, averaged over $6 \mathrm{sec}$.

data after increasing or decreasing the mean red LED level. Decreasing the red LED level has little effect on the phase template, since the green diode already dominates the response. Increasing the red LED level brings about a shallower slope to the curve, since now the red light begins to be significantly absorbed by the pigment. Equations 1 and 2 can be modified by multiplying $S_{563 \mathrm{R}}$ by the appropriate factor and amplitude and phase templates generated. The solid curves are least-squares fits of these templates,

Female $563 \mathrm{~nm}$ dichromat (M5)

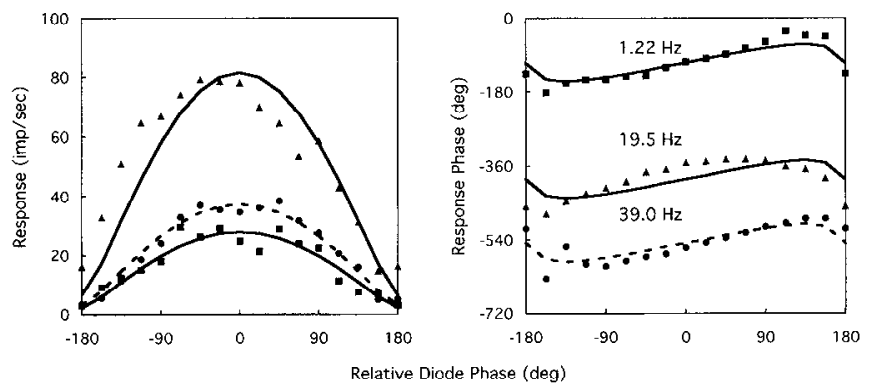

Figure 6. If the phase template is a reliable means of identifying the cone pigment, then its shape should be independent of temporal frequency. Response amplitude and phase from a MC-cell from a dichromatic, $563 \mathrm{~nm}$ female are shown for three temporal frequencies (1.22, solid squares; 19.5, solid triangles; and $39.0 \mathrm{~Hz}$, open squares). For the phase data, solid lines are templates shifted on the ordinate to attain a least-squares fit. With increasing temporal frequency, the data and fit tcmplates shift downwards due to the phase delay in the response. For the $19.5 \mathrm{~Hz}$ data, the phase data show some advance around $\theta=0$, probably due to the phase advance associated with contrast gain control. Amplitude data have been fitted by scaling the predicted amplitude template. 


\section{Male Dichromat, $543 \mathrm{~nm}(\mathrm{M} 17)$}
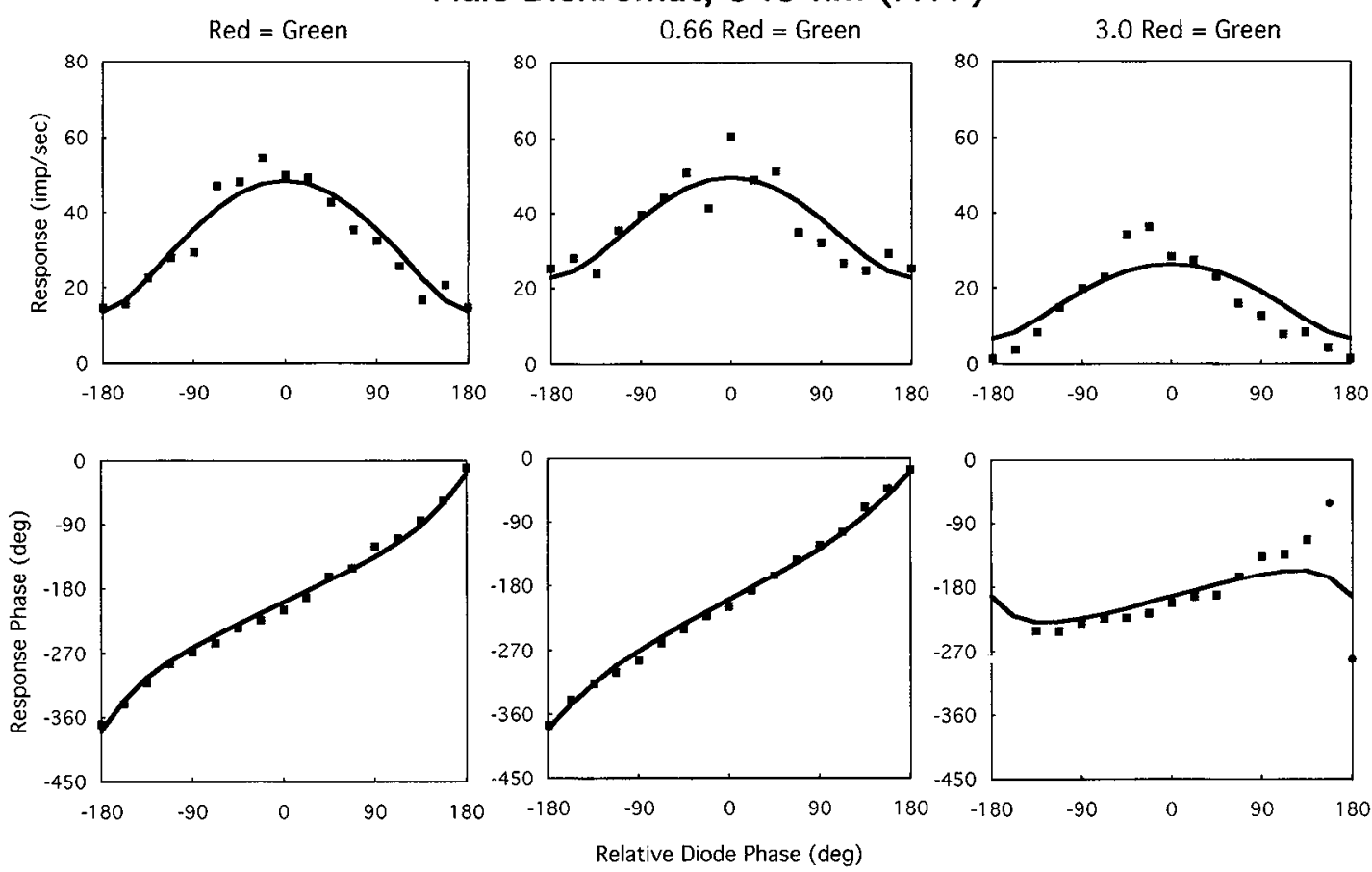

Figure 7. Confirmation of pigment identification by changing the intensity of the red LED, leaving modulation depth constant. Data were obtained from a $543 \mathrm{~nm}$ dichromatic male. Three levels of red light were used, the standard setting, and 0.6 and 5.0 times the standard setting. Changing red LED level has a minor effect on the amplitude template, but can have a major effect on the phase template. Solid lines show templates predicted by scaling the appropriate parameter in Equations 1 and 2 and fitted to the data. Open symbols show phase values at which response amplitude fell below $8 \mathrm{imp} / \mathrm{sec}$. These were not used in the fits. Data were acquired with $50 \%$ diode modulation at $4.88 \mathrm{~Hz}$, averaged over 6 sec.

again achieved by shifting the phase template vertically and using a single scaling parameter for amplitude. The templates provide a satisfactory description of the data. In the phase plots triangles indicate points for which amplitude fell below $8 \mathrm{imp} / \mathrm{sec}$. Phase measurements then became unreliable, and these points were not used in the fits. The data are consistent with the predictions from Equations 1 and 2 . With the $563 \mathrm{~nm}$ pigment, characteristic changes in the phase and amplitude templates are also expected on changing the red LED level, and these were confirmed experimentally.

The analyses shown in Figures 5-7 were characteristic for PCand MC-cells recorded from dichromats, and enabled us to determine the pigment of any given animal. However, those neurons from dichromatic monkeys with responses to chromatic pulses as shown in Figure $2 B$ showed more complex behavior with the phase-varying stimulus. This is illustrated in Figure 8 . The data points show amplitude and phase measurements for the cell of Figure $2 B$ at four of six temporal frequencies tested. The curves are fits of a model described below. At 1.22 (not shown) and 2.44 $\mathrm{Hz}$ response phase and amplitude were consistent with the $563 \mathrm{~nm}$ pigment present in this animal. At higher temporal frequencies the relative diode phase of the response minimum begins to alter, and this is associated with a change in the shape of the phase relationship. As discussed in Smith et al. (1992), changes of this sort require an interaction between two pigments; they cannot be generated through, for example, center-suround interaction with just one pigment. In particular, a change in slope of the phase relationship as a function of temporal frequency indicates a change of spectral sensitivity, since the ratio of the effectiveness of the red and green LEDs must be changing. Since the animal only had one cone pigment in the M-L range $(563 \mathrm{~nm})$, we considered the possibility of rod-cone interaction. If the cell received excitatory signals from both the $563 \mathrm{~nm}$ cone and rods, a rod response delayed with respect to the cone signal might bring about the cffects obscrved. To test this possibility, data were fitted with a variant of the model developed by Smith et al. (1992).

Cell response phase, $R_{\text {phasc }}$, and relative response amplitude, $R_{\text {amp }}$ are given by

$$
\begin{aligned}
R_{\text {amp }}= & {\left[\left(W P_{5633 \mathrm{amp}}\right)^{2}+\left((1-W) P_{\text {rodaimp }}\right)^{2}\right.} \\
& \left.+\cos \left(P_{56.3 \mathrm{phase}}-P_{\text {rodphase }}+\phi_{56.3}-\phi_{\text {rod }}\right)\right]^{0.5 .5}
\end{aligned}
$$

and

$$
R_{\text {phase }}=\arctan \left[\begin{array}{c}
W P_{563 \text { amp }} \sin \left(P_{563 \text { phasc }}+\phi_{563}\right) \\
+(1-W) P_{\text {rodamp }} \sin \left(P_{\text {rodphasc }}+\phi_{\text {rod }}\right) \\
W P_{563 \text { amp }} \cos \left(P_{563 \text { phase }}+\phi_{563}\right) \\
+(1-W) P_{\text {rodamp }} \cos \left(P_{\text {rodphase }}+\phi_{\text {rod }}\right)
\end{array}\right]
$$

where $P_{56,3 a m p}$ and $P_{563 \text { phase }}$ are given by Equations 1 and 2. Since only the green light is absorbed by the rods to a significant extent, $P_{\text {rodamp }}$ is a constant and was set to unity and $P_{\text {rodphase }}=$ $\theta$, the phase of the green LED. $W, \phi_{563}$, and $\phi_{\text {rod }}$ are free parameters. $W$ is a weighting term (the absorption spectra were normalized to the same height for the calculations) and the other two terms represent the actual phase of the cone and rod inputs as expressed in the ganglion cell response. These parameters may depend on temporal frequency; the equations only refer to a single frequency. Phase rather than amplitude data were fitted (Smith et al., 1992) using a nonlinear regression procedure (IMSL). In the majority of cases fits were satisfactory, for the cell shown in Figure 8 and for other neurons. 

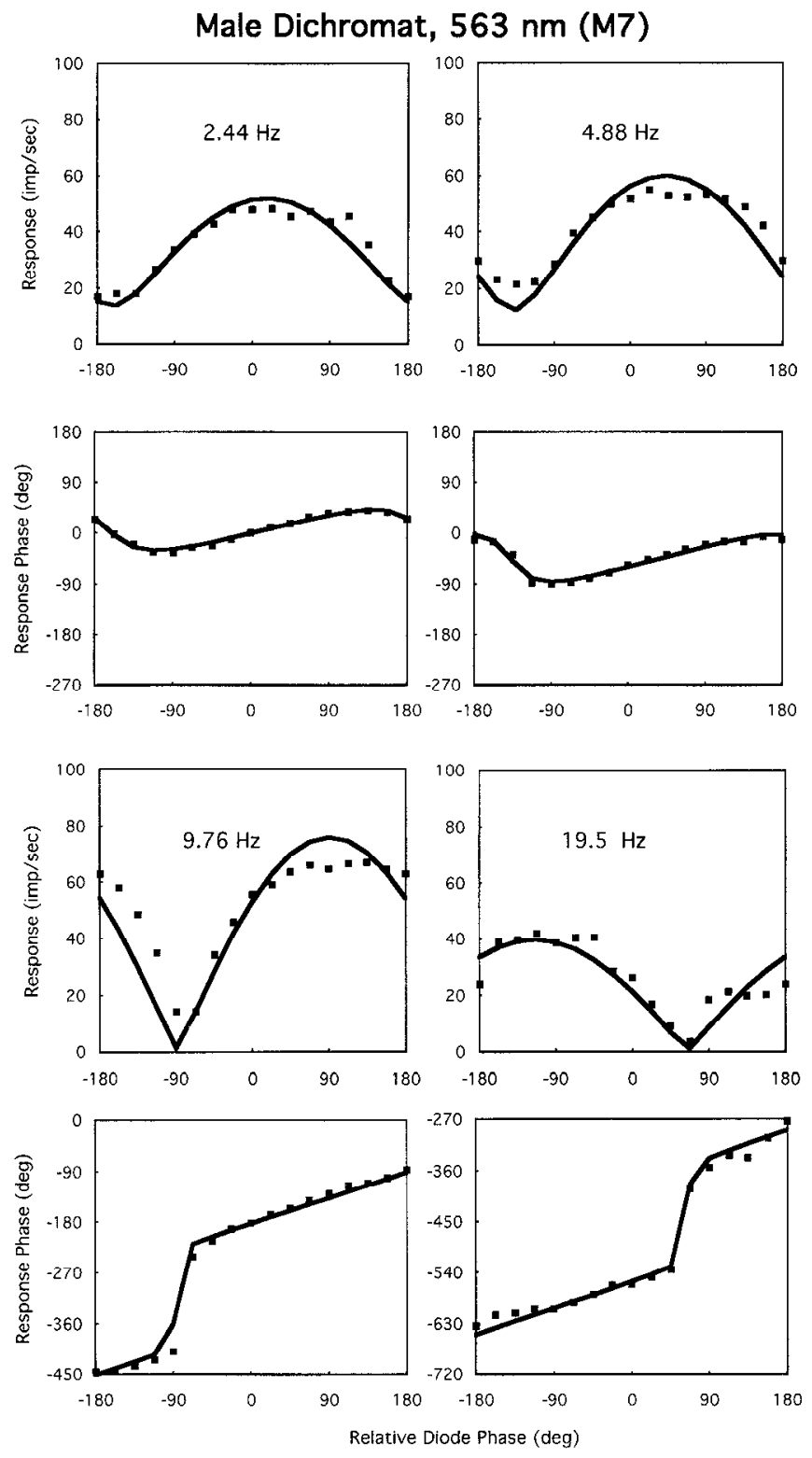

Figure 8. Amplitude and phase data from a PC-cell from a $563 \mathrm{~nm}$ dichromatic male for four different temporal frequencies. The position of the amplitude minimum and the shape of the phase data are frequency dependent. This indicates interaction of two visual pigments. Data were modelled using Equations 3 and 4 described in the text. We hypothesised that the $563 \mathrm{~nm}$ pigment was interacting with rod signals. Fit parameters were; $2.44 \mathrm{~Hz} ; 1.0(W), 5.7^{\circ}\left(\phi_{563}\right)-\operatorname{deg}\left(\phi_{\text {rod }}\right) ; 4.88 \mathrm{~Hz}$; $0.60(W),-49.0^{\circ}\left(\phi_{563}\right) 173.6^{\circ}\left(\phi_{\mathrm{rod}}\right) ; 9.76 \mathrm{~Hz} ; 0.39(W),-136.4^{\circ}\left(\phi_{563}\right)$ $-267.0^{\circ}\left(\phi_{\text {rod }}\right) ; 19.76 \mathrm{~Hz} ; 0.35(W),-256.1^{\circ}\left(\phi_{563}\right)-472.1^{\circ}\left(\phi_{\text {rod }}\right)$. The rod input at $2.44 \mathrm{~Hz}$ was too weak to be measured. Amplitude templates have been fitted using a single scaling parameter. Other details as in earlier figures.

The values $W, \phi_{563}$, and $\phi_{\text {rod }}$ derived from the phase fits were inserted into Equation 3 and the amplitude function scaled to give the best least-squares fit. The amplitude fits in Figure 8 are satisfactory considering the parameters were derived from phase data, and demonstrate that the model is behaving in a reasonable manner. Fit parameters are given in the figure caption. The rod/ cone weighting was low at low frequency, and data at 1.22 and $2.44 \mathrm{~Hz}$ could be fitted assuming only input from the $563 \mathrm{~nm}$ cone. Weighting increased at 9.76 and $19.52 \mathrm{~Hz}$. It was apparent from the analysis that rod and cone signals had to be summed rather than differenced. The lag of the rod behind the cone signal increased with frequency in an approximately linear manner, with a slope of $12 \% \mathrm{~Hz}$, which in terms of a latency difference would be about $33 \mathrm{msec}$. This is similar to the value estimated for the difference between cat rods and cones (Troy et al., 1993).

The data and fits in Figure 8 support the hypothesis that a proportion of PC-cells in the dichromatic marmoset LGN receives significant rod input even at the relatively high retinal illuminance in the present experiments. This contrasts strongly with data from PC-cells in the macaque where rod input, if present, is usually weak and only evident at scotopic levels (Virsu and Lee, 1983; Virsu et al., 1987; Purpura et al., 1988). Also, in every case rod and cone signals appeared to add rather than entering into an opponent relationship.

\section{Cone opponency in trichromats}

The phase protocol provides a ready means for detecting cone opponency and assessing cone balance. If a cell receives opponent input from two cones, then there is a response minimum when the lights are in phase $\left(0^{\circ}\right.$; corresponding to luminance modulation) and a response maximum when the lights are out of phase $\left(180^{\circ}\right.$; corresponding to chromatic modulation). Response phase changes rapidly near $0^{\circ}$ instead of near $180^{\circ}$, as was the case for dichromats. In macaques, red-green opponent cells respond in a characteristic way to this stimulus (Smith et al., 1992). Trichromatic animals could be readily identified with this stimulus since cone opponency was immediately apparent in most cells in the parvocellular layers. However, some cells appeared to be dominated by either the 563 or $543 \mathrm{~nm}$ cone. Responses of these cells were difficult to distinguish from those of PC-cells in dichromats.

Data of a typical opponent cell, classified as a green-on, are shown in Figure 9, for four of the six frequencies tested. The solid curves are fits of a model. In contrast to the nonopponent cells of Figures $5-7$, at low frequency there is a maximum response to chromatic modulation $\left(180^{\circ}\right)$, with the cell firing in phase with the green light. There is a minimum response to luminance modulation. The minimum response is associated with a rapid phase transition. With increasing frequency, the relative diode phase of minimum response and the phase transition shift away from $0^{\circ}$ to negative values. This behavior is very similar to that of green-on opponent cells in the macaque, in which it is attributable to a frequencydependent phase difference between the opponent cone inputs, consistent with a center-surround latency difference of a few milliseconds (Smith et al., 1992).

We fitted cell responses using the full version of the PC-cell model in Smith et al. (1992):

$$
\begin{aligned}
R_{\text {amp }}= & {\left[\left(W P_{563 \text { amp }}\right)^{2}+\left((1-W) P_{543 \text { amp }}\right)^{2}\right.} \\
& \left.+\cos \left(P_{563 \text { phase }}-P_{543 \text { phase }}+\phi_{563}-\phi_{543}\right)\right]^{0.5}
\end{aligned}
$$

and

$$
R_{\text {phase }}=\arctan \left[\begin{array}{c}
W P_{563 a \mathrm{amp}} \sin \left(P_{563 \mathrm{phase}}+\phi_{563}\right) \\
\frac{+(1-W) P_{543 \mathrm{amp}} \sin \left(P_{543 \mathrm{phase}}+\phi_{543}\right)}{W P_{563 \mathrm{amp}} \cos \left(P_{563 \mathrm{phase}}+\phi_{563}\right)} \\
+(1-W) P_{543 \mathrm{arnp}} \cos \left(P_{543 \mathrm{phase}}+\phi_{543}\right)
\end{array}\right]
$$

Equations 5 and 6, which describe response amplitude and phase, are identical to Equations 3 and 4 except that the $P_{\text {rodamp }}$ and $P_{\text {rodphase }}$ terms have been replaced by $P_{543 a m p}$ and $P_{543 \text { phasc }}$, 
Female Trichromat, 543-563 nm (M13)
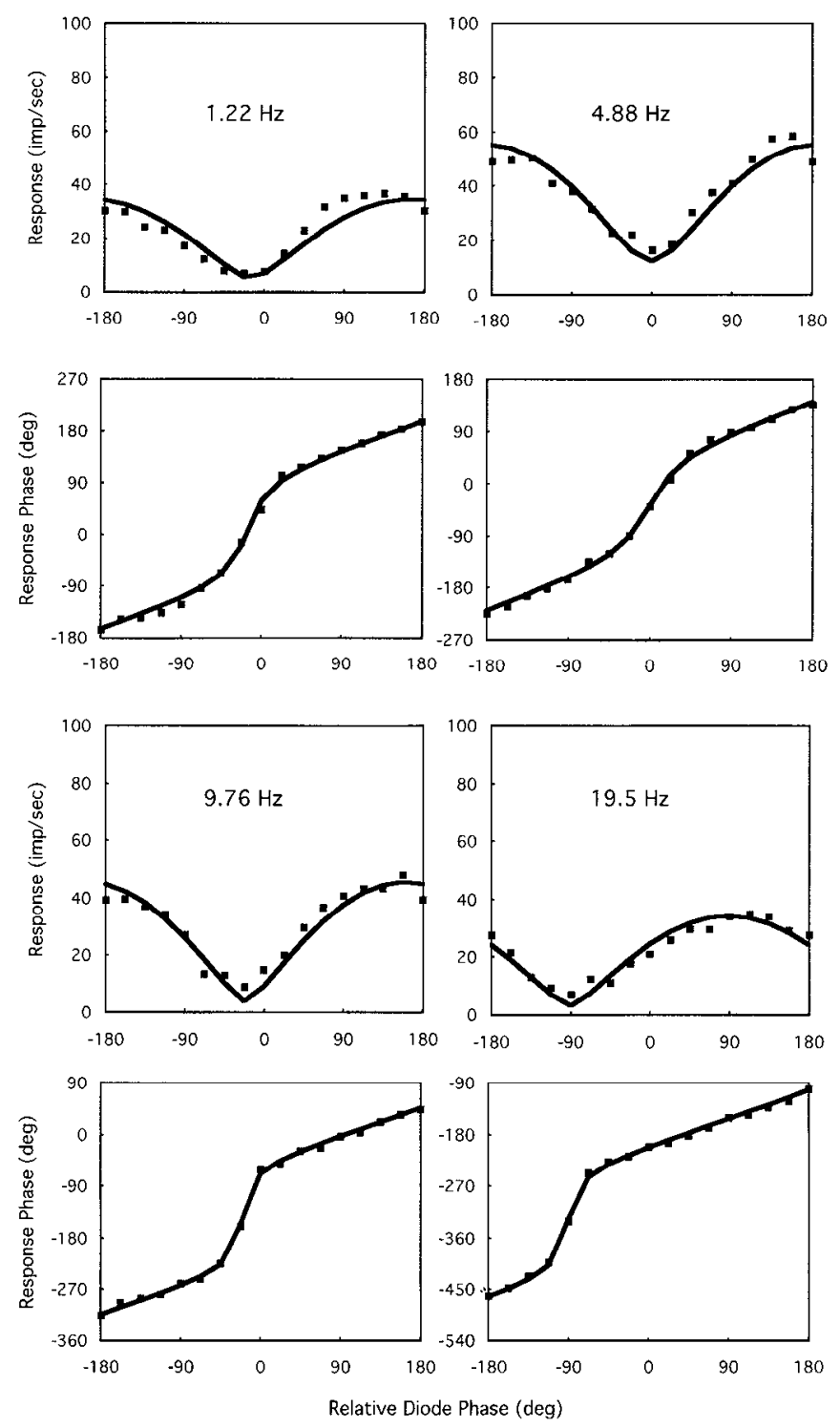

Figure 9. Amplitude and phase data from a green-on PC-cell from a $543-563 \mathrm{~nm}$ trichromatic female for four different temporal frequencies. There is an amplitude minimum and abrupt phase change near $0^{\circ}$ (luminance modulation) at low temporal frequencies. The position of the amplitude minimum and the shape of the phase data are frequency dependent. This indicates an interaction of the two cone pigments as in the macaque. Data were modeled using Equations 3 and 4 described in the text cxcept that the $543 \mathrm{~nm}$ conc was substituted for the rod terms. Fit parameters were; $1.22 \mathrm{~Hz} ; 0.40(W),-166.6^{\circ}\left(\phi_{563}\right) 16.1^{\circ}\left(\phi_{543}\right)$; $4.88 \mathrm{~Hz} ; 0.39(W),-219.1^{\circ}\left(\phi_{563}\right)-39.0^{\circ}\left(\phi_{543}\right) ; 9.76 \mathrm{~Hz} ; 0.41(W)$, $-317.2^{\circ}\left(\phi_{656}\right)-133.3^{\circ}\left(\phi_{543}\right) ; 19.76 \mathrm{~Hz} ; 0.41(W),-479.2^{\circ}\left(\phi_{563}\right)$ $-278.1^{\circ}\left(\phi_{543}\right)$. Signals for the $563 \mathrm{~nm}$ inhibitory cone are delayed relative to the $543 \mathrm{~nm}$ cone by ca. $1 \mathrm{deg} / \mathrm{Hz}$. Amplitude templates have been fitted using a single scaling parameter. Other details as in earlier figures.

which were derived for the $543 \mathrm{~nm}$ pigment from Equations 1 and 2. The equations represent a vector combination of the 543 and $563 \mathrm{~nm}$ cone signals. Again, we chose to fit the phase data, adjusting the three free parameters, $W, \phi_{563}$, and $\phi_{543}$. to achieve the best least-squares fit. The amplitude data was predicted using these three fitted parameters using a scaling factor. As in Figure 8 , a satisfactory fit of phase data was achieved at all frequencies,

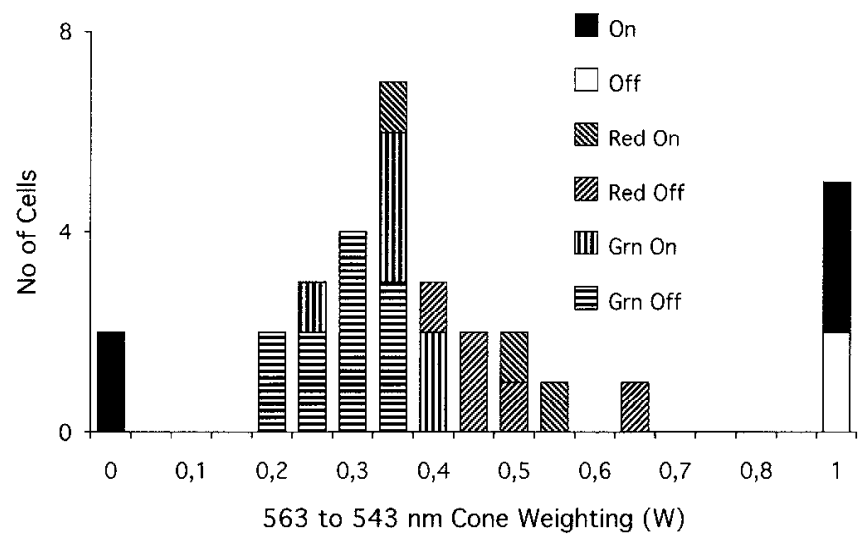

Figure 10. Cone weighting distributions for 32 PC-cells from 543$563 \mathrm{~nm}$ trichromatic animals. Values of $W$ were obtained from fitting Equations 3 and 4 after modification for the two cone pigments rather than cones and rods. Cells have been divided according to classification.

and the parameters from the phase fits capture the amplitude data. Fit parameters are included in the figure caption. The data and fits in Figure 9 closely resemble results from green-on cells in the macaque (Smith et al., 1992; Fig. 3). For example, the amplitude minimum has shifted by ca. $-90^{\circ}$ by $19.52 \mathrm{~Hz}$, within the range for macaque cells. Red-on cells also closely resembled macaque data, with a shift of the amplitude minimum toward positive values of relative diode phase.

Of 32 PC-cells studied with the phase protocol in trichromats, 25 showed indications of cone opponency $(80 \%)$. For neurons in which opponency was weak or absent, the model was not well constrained by the data. In order to obtain cone weightings for these cells, we permitted only in or out of phase cone signals and restricted the analysis to low temporal frequencies. Figure 10 shows the distribution of cone weightings for the cell sample. Cells have been grouped according to the fitting parameter, $W$. Higher values indicate greater weight for the $563 \mathrm{~nm}$ pigment. With the normalization used, the cone weights required to give no response to luminance modulation (at low frequency) was 0.41 . Weightings observed distribute around this value, as in the cone weighting distribution in macaques (Smith et al., 1992; see Fig. 12D). Cells have been grouped into red on, red off, green on and green off categories, based on the response to luminance modulation and the direction of the cone opponency. Red on and red off cells tend to have larger values of $W$ than green on and green off cells, although there is considerable overlap in the distributions. This is also the case in the macaque. For the cells in which no opponency was apparent, it appeared that one or other cone dominated the cell response, that is, cells' phase data resembled that from dichromatic animals and could be fitted by the appropriate template. These cells are also represented in Figure 10 as "On" and "Off" cells with cone weightings $(W)$ of 0 (543 $\mathrm{nm}$ pigment) and 1 (563 $\mathrm{nm}$ pigment).

MC-cells from trichromats also showed features seen in macaque MC-cells. One of these was a frequency-doubled response to chromatic modulation. This is illustrated in Figure 11A. Spike density tracings are shown for an MC-cell to $9.76 \mathrm{~Hz}$ luminance modulation, to which there is a vigorous response, and to 9.76 $\mathrm{Hz}$ chromatic modulation. The relative intensities of the red and green lights had been adjusted to minimize the first-harmonic response. A response at twice the stimulus frequency is seen. In the macaque, this second-harmonic response appears to be due to a nonlinearity of $\mathrm{M}$ - and L-cone summation (Lee et al., 

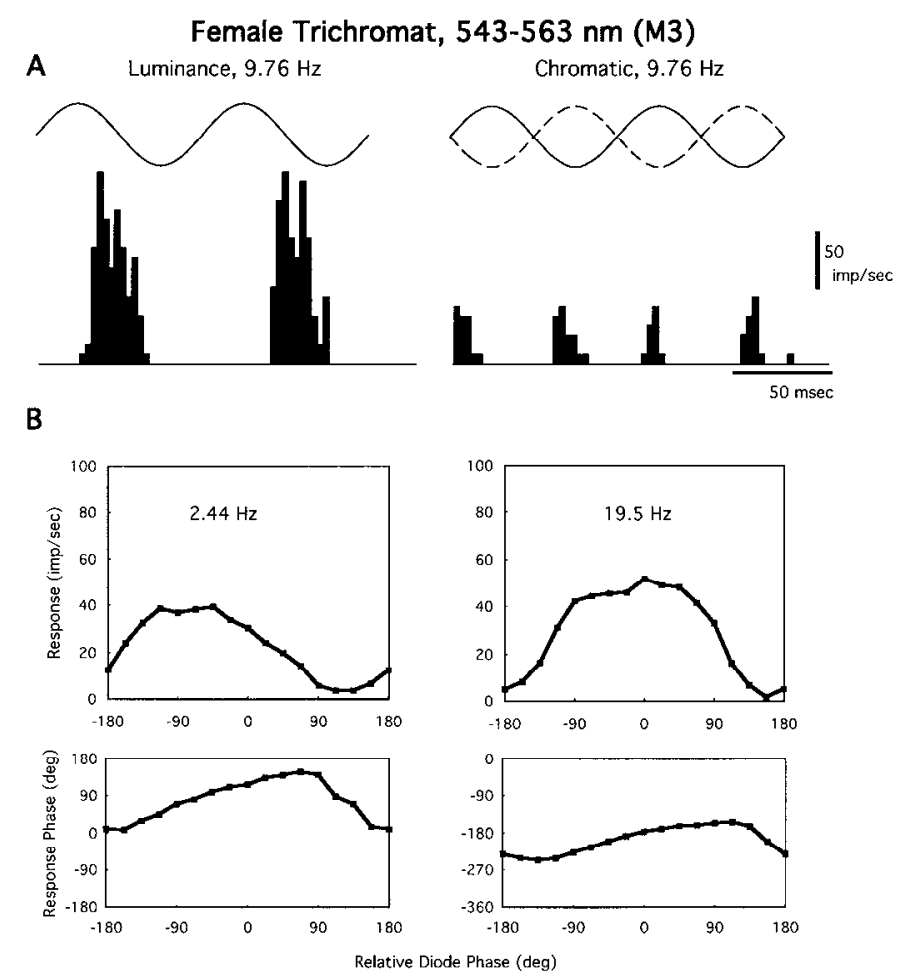

Figure 11. A, Responses of a MC-cell from a trichromatic animal to luminance and chromatic modulation at $10 \mathrm{~Hz}$. Two cycles of response are shown. To chromatic modulation, there is a response at twice the modulation frequency. This behavior is similar to MC-cells of the macaque. $B$, Amplitude and phase data for a $\mathrm{MC}$-cell at two frequencies as a function of relative diode phase. At low frequencies, the phase of least response is in the red-leads-green region. As frequency increases, the phase of least response moves closer to $180^{\circ}$. This is again similar to MC-cells of the macaque. Other details as in earlier figures.

1989a), since it is absent to modulation along a tritanopic confusion line.

Changing the relative phase of the red and green lights reveals in MC-cells of the macaque a shift of the relative phase of minimum response away from $180^{\circ}$ at low temporal frequencies. As frequency is increased, the relative phase of minimum response moves toward $180^{\circ}$, as expected from an achromatic cell (Smith et al., 1992). This behavior was also observed in trichromat marmoset MC-cells and is illustrated in Figure $11 \mathrm{~B}$. Amplitude and phase have been plotted as a function of relative diode phase at two temporal frequencies. At $2.44 \mathrm{~Hz}$, the relative phase of minimum response is shifted away from $180^{\circ}$ toward the "red-leadsgreen" condition, and this is associated with a rapid change in response phase. At $19.52 \mathrm{~Hz}$, the relative phase of minimum response has shifted toward $180^{\circ}$. These effects are similar to those seen in MC-cells of the macaque (Smith et al., 1992; Fig. 10 ), in which this behavior appears to originate through a chromatic, opponent input to the receptive field surround. Modeling this behavior requires a more elaborate approach, and was not attempted for the data in Figure $11 B$, in which the points have been connected with straight-line segments.

We conclude that LGN cell behavior in trichromatic marmosets resembles in many respects that observed in macaques. The interaction of opponent mechanisms in cone-opponent cells appears to be similar, with a center-surround delay of similar size to that observed in the macaque. Also, a frequency-doubled response to chromatic modulation was found in MC-cells of the marmoset as in

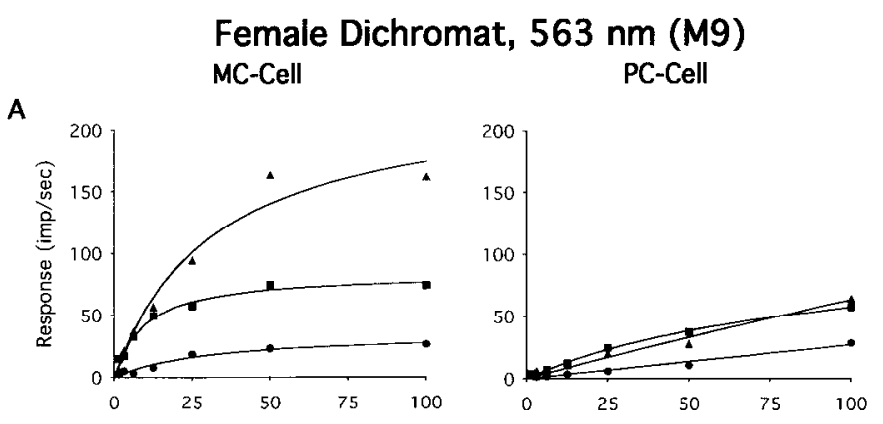

B
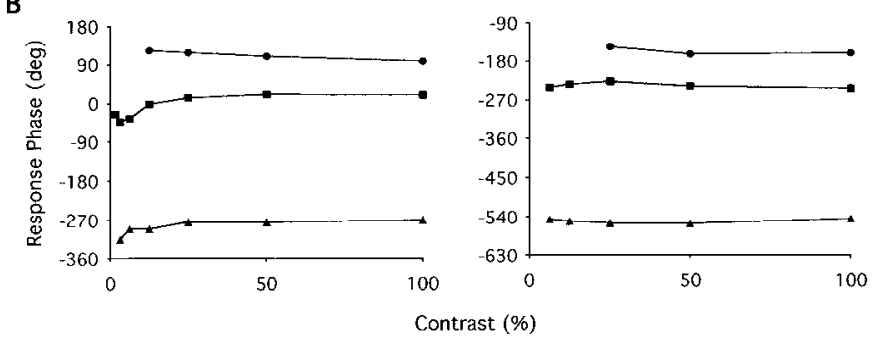

C

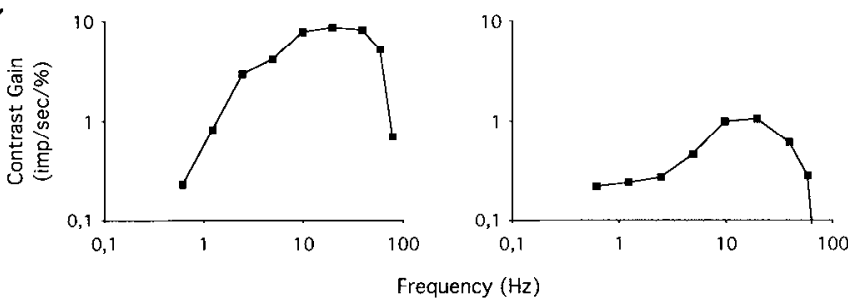

Figure 12. A, Response amplitude and $\mathrm{B}$ phase as a function of luminance contrast for a MC- and a PC-cell from a dichromatic $563 \mathrm{~nm}$ fenale at three temporal frequencies $(1.22 \mathrm{H} /$, circles; $9.76 \mathrm{~Hz}$, squares; $19.5 \mathrm{~Hz}$, triangles). Responses have been fitted by Naka-Rushton functions. The MC-cell shows indications of response saturation and phase advance with increasing contrast, probably indicative of a contrast gain control mechanism. This is especially apparent at $9.76 \mathrm{~Hz}$. The $\mathrm{PC}$-cell is less responsive with a more linear contrast-response relation and no indication of phase advance. $C$, Contrast gain as a function of temporal frequency for the two cells shows the MC-cell to be more responsive.

the macaque, and the shift in the MC-cell response minimum away from $180^{\circ}$ at low temporal frequencies also appears similar in macaque and marmoset. However, the presence of a significant fraction of achromatic cells within the parvocellular layers has not been observed in macaque recordings.

\section{Cell responsivity as a function of temporal frequency}

For $58 \mathrm{PC}$ - and $17 \mathrm{MC}$-cells, we also recorded responses to luminance modulation as a function of contrast and temporal frequency. In trichromatic animals, the response to chromatic modulation was also recorded. Figure 12 shows data from a MCand a PC-cell from a dichromatic animal. To ensure that the temporal response of the cells were not modified by LGN inhibition, the data shown were acquired from an $\mathrm{S}$ - or prepotential (the PC-cell) and a retinal afferent from the optic tract (the MC-cell). However, the pattern of response from LGN relay cells was similar to that shown. Figure $12 A$ shows the amplitude of the first harmonic as a function of contrast at three temporal frequencies $(1.22,9.76$, and $39.02 \mathrm{~Hz})$. For the MC-cell, especially at $9.76 \mathrm{~Hz}$ (solid squares), response amplitude increased rapidly as a function of contrast to saturate at a contrast of about $20 \%$. In Figure $12 B$, response phase has been plotted against 

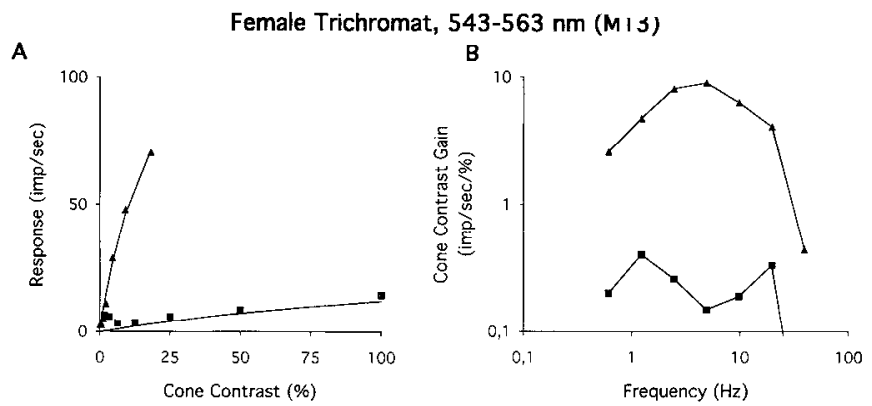

Figure 13. A, Response amplitude as a function of mean cone contrast for chromatic (triangles) and luminance modulation (squares) for a cone-opponent PC-cell from a trichromatic animal. Responsivity is greater to chromatic modulation. This can also be seen in the contrast gain curves in $B$.

contrast for those responses for which the first harmonic amplitude exceeded $8 \mathrm{imp} / \mathrm{sec}$. An advance of response phase with increasing contrast can be seen in the MC-cell, which is especially apparent at $9.76 \mathrm{~Hz}$. This rapid response saturation accompanied by a phase advance is characteristic of the operation of a contrast gain control (Shapley and Victor, 1978). In the PCcell, responsivity as a function of contrast has a much shallower slope and there is much less indication of response saturation. No phase advance with contrast is present. This difference between PC- and MC-cells is very similar to the macaque (Benardete et al., 1992; Lee et al., 1994; Yeh et al., 1995). The amplitude data in Figure $12 \mathrm{~A}$ were fitted with Naka-Rushton functions (Naka and Rushton, 1966), shown by the solid lines. The initial slope of these functions gives a measure of contrast gain. This is plotted as a function of temporal frequency in Figure $12 C$. The MC-cell shows a band-pass function with a peak sensitivity about a factor of ten greater than for the PC-cell. This difference in contrast gain resembles the difference in responsivity between MC- and PC-cells of the macaque (Kaplan and Shapley, 1986; Lee et al., 1990); but it is unexpected that it should also apply to these pathways in dichromatic marmosets.

Figure 13A demonstrates the relation between first harmonic amplitude and cone contrast for a PC-cell afferent (recorded as a prepotential) from a trichromatic female for luminance and chromatic modulation at $9.76 \mathrm{~Hz}$. The abscissa is expressed in terms of the Inean cone contrast for the 543 and $563 \mathrm{~nm}$ cones. For luminance modulation cone contrasts are identical in the two pigments and $100 \%$ contrast can be achieved. For chromatic modulation, we used equal modulation depths of the two LEDs. The equivalent of the luminosity function is unknown for the marmoset, but counterphase modulation of the LEDs is likely to have provided an effective chromatic stimulus. For chromatic modulation, it is appropriate to interpret responses in terms of the cone modulation evoked by the stimulus. In the old world-primate, peak absorptions of the middle and long wavelength cones are further apart than for the 543 and $563 \mathrm{~nm}$ pigments of the marmoset. In relation to the dominant wavelengths of the LEDs used, this results in lower cone contrasts being achievable for the 543 and 563 marmoset pigments than for the old-world primate pigments. For the $543 \mathrm{~nm}$ pigment, maximum modulation depth was $33 \%$ and for the $563 \mathrm{~nm}$ pigment $16 \%$, resulting in a mean of $24.5 \%$. Greater cone modulation depths can be achieved from the macaque cone pigments using the same LEDs (Smith et al., 1992). After cell responsivity has been scaled by this factor, the response to chromatic modulation of the opponent PC.cell in Figure $13 \mathrm{~A}$ can be seen to be much more vigorous per unit of cone contrast than for luminance modulation. This behavior resembles that of M-L opponent cells of the macaque (Lee et al., 1993). Data have been fitted with the Naka-Rushton function. Cone contrast gain is plotted as a function of temporal frequency for luminance and chromatic modulation for the cell of Figure $12 \mathrm{~A}$ in Figure $12 B$. Cone contrast gain is much higher in the latter case.

These data show that the similarity between the PC- and MCpathways of macaque and marmoset extend to the difference in contrast gain between the two pathways, and to the presence and absence of contrast gain control in $\mathrm{MC}$ - and PC-cells respectively. This appears to be the case for both trichromatic and dichromatic animals.

\section{Discussion}

Recent interest in vision in new-world primates has centered around the inheritance of the pigment genes. It has been suggested that either trichromacy evolved separately in new-world and old-world families or that it evolved in old-world primates from an ancestral, new-world pattern through gene duplication (Hunt et al., 1993). It is remarkable that so many properties of the PC- and MC-cells of trichromatic old-world primates are also present in trichromatic marmosets. Since the first explanation would require parallel evolution to account for the similarity in retino-geniculate physiology between trichromatic old and new-world animals, the present data favor the latter explanation for the origin of old-world trichromacy; that is, from a previously established polymorphism.

The physiological and anatomical consequences of this polymorphism remain to be fully explored. Since the present results suggest that in trichromatic marmosets (and presumably in other trichromatic new-world primates) PC- and MC-cell responses closely resemble those in macaques, the retinal machinery associated with trichromacy must be fully expressed if two middleto-long wavelength pigments are present. Nevertheless, the present results contain some puzzling features.

If the new-world primate represents a first step toward the development of full trichromacy as in old-world primates, then presumably some ancestor possessed only a single pigment gene in the middle-to-long wavelength range. It is unknown if this ancestor possessed parvo- and magnocellular pathways, but it seems likely given the prevalence of these systems in modern primates. One hypothesis might be that male new-world primates, as obligatory dichromats, should show the anatomy and physiology of this ancestral form, but this seems unlikely. Anatomically, it appears that the midget, parvocellular ganglion cell system is very similar in dichromatic and trichromatic marmosets (Martin et al., 1995). If the midget ganglion cell system had developed as an aid to cone specificity in color opponency (Shapley and Perry, 1986), then it is uncertain why it should be present in both dichromats and trichromats. On the other hand, if the parvocellular system had developed as an aid to precise spatial vision (Wässle and Boycott, 1991), low responsivity and sluggish responses might be a disadvantage. It is possible these properties may reflect another functional requirement, such as the derivation of an achromatic brightness signal (Valberg and Seim, 1991). In any event, trichromacy in new-world primates depends on the inheritance of two X-chromosomes with pigment genes differing in only a few base pairs (Williams et al., 1992). Nevertheless, when expressed in the cone mosaic, the two pigments then appear to be able to invoke a retinal organization, such as opponent responses, characteristic of trichromatic old-world primates. How this may occur is an intriguing developmental question. 
In this article we have termed animals dichromats or trichromats based on physiological criteria, the number of pigments being confirmed by genetic analysis. This is an inference, since the terms refer to an animal's behavioral capacity for color vision. Nevertheless, all current evidence suggests that di- and trichromacy and the presence of one or two long-wavelength pigments are firmly linked in new-world primates (Tovee et al., 1992; Jacobs et al., 1993).

Confirming an earlier report from another new-world primate, the owl monkey (Sherman et al., 1976), cells of the parvocellular and magnocellular systems of marmosets showed sustained and very transient responses, respectively. In this respect, the two systems resemble those of the old-world primate. This similarity extends through other features of the cells' responses, for example, the presence or absence of a contrast gain control. Without more evidence, however, it would be premature to assume too great a homology. There may be differences in organization between of the visual pathway between new- and old-world primates (e.g., the lack of ocular dominance columns in new-world animals; Hendrickson et al., 1978), and the organization of parvocellular and magnocellular systems may turn out to differ, for example, with respect to rod input.

PC-cells from trichromatic marmosets showed much higher contrast gain to chromatic modulation than to luminance modulation, after correction for the cone modulation evoked by the stimulus. This has also been observed in the macaque (Lee et al., $1989 \mathrm{~b}$ ). The peak absorptions for the marmoset pigments differ from those of old-world species, such that with the red-green modulation used a smaller cone contrast signal is available.

Although in many respects the physiology of PC- and MCcells in trichromatic marmosets appeared similar to that of the macaque, we did observe a proportion of PC-cells without cone opponency. This was not obviously dependent on retinal eccentricity. Although in the old-world monkey some early reports suggested the presence of achromatic cells in the parvocellular layers (Wiesel and Hubel, 1966), quantitative studies either involving chromatic adaptation (de Monasterio et al., 1975; Padmos and van Norren, 1975) or modulation in a color space (Derrington et al., 1984; Lee et al., 1987) have concurred in finding very few if any PC-cells in the macaque without cone-opponency. Such cells in the marmoset may reflect an additional PC-cell class. On the other hand, it is possible that in the new-world primate cone distribution in local retinal regions could be patchy due to $\mathrm{X}$-chromosome inactivation during cell division for the receptor mosaic. This possibility has been extensively discussed with respect to human carriers of genes for color deficiency (Born et al., 1976; Nagy et al., 1981; Jordan and Mollon, 1993). Then, it might occur that a $\mathrm{PC}$-cell receptive field contained cones of only one pigment type, forcing the ganglion cell to become nonopponent. Comparison of properties of cells with neighboring receptive fields would be of interest, but with LGN recordings, receptive fields of successively recorded cells were too far apart to be able to make such comparisons.

The low contrast gain to luminance modulation in PC-cells of dichromats was unexpected. In PC-cells of the macaque, low contrast sensitivity to luminance modulation has been attributed to cancellation of opponent cone signals, since when expressed in terms of cone contrast, PC-cell sensitivity to chromatic modulation is not much inferior to MC-cell sensitivity to luminance modulation (Lee et al., 1990, 1993). We tested a number of marmoset cells with luminance modulation of spots of different sizes, and it did not appear that the poor responsivity was due to surround inhibition of a center response (Jacobs and Yolton, 1970). Neither did it appear that poor responsivity was due to a high level of inhibition within the LGN, since similar data were obtained from S-potential or optic tract recordings as from LGN relay cells. It was also noteworthy that most PC-cells in both dichromats and trichromats were unable to respond to frequencies much above $30-40 \mathrm{~Hz}$. MC-cells responded to higher frequencies $(50-80 \mathrm{~Hz})$.

The incidence of cells with S-cone input was not obviously higher in dichromatic than in trichromatic animals. We had considered the possibility of an increase in the number of blueyellow opponent cells in dichromats, reflecting an expansion of this opponent system when red-green opponency was absent. This did not occur, consistent with the finding that this pathway is anatomically quite distinct from the midget system (Daccy and Lee, 1994), precluding its expansion into the midget cell population. In dichromat PC-cells with rod input, it was also of note that the rod input was always synergistic to the center response, rather than entering into an opponent relationship.

The presence of significant rod input in some PC-cells in the dichromatic marmoset is a marked difference to PC-cells of the macaque, especially in view of the high retinal illuminances employed in the present experiments. In extensive recordings from macaque PC-cells using the phase protocol, we have never observed responses such as those in Figure 8 (B. B. Lee, V. C. Smith and J. Pokorny, unpublished observations) and weak rod inputs could only be detected below cone threshold, in accordance with other data in the literature (Virsu and Lee, 1983; Virsu et al., 1987; Purpura et al., 1988). In the marmoset, the strength of rod input was variable and not obviously associated with retinal eccentricity. We do not know whether the cells in which rod input was demonstrable represent a separate class or the extreme of a continuum. The latter alternative seems more likely, since there is no anatomical evidence for more than one class of midget-like cells in the retina (Ghosh et al., 1994), and rod input readily can be revealed in many marmoset PC-cells at low light levels (J. Kremers, personal communication). The presence of cone opponency in trichromatic animals made any additional input from a third, rod, pigment difficult to detect, and the extent of rod input in trichromats remains uncertain. In any event, a difference in retinal organization for rod signals may exist between old and new world primates. The only nocturnal primate species comes from the new-world (the owl monkey), and the strong rod input to marmoset PC-cells may be an indication of ancestral adaptation to a more crepuscular existence.

\section{References}

Benardete EA, Kaplan E, Knight BW (1992) Contrast gain control in the primate retina: P-cells are not X-like, some M-cells are. Visual Neurosci 8:483-486.

Born G, Grützner P, Hemminger H (1976) Evidenz für eine Mosaikstruktur der Netzhaut bei Konduktorinnen für Dichromosie. Human Genetics 32: 189-196.

Dacey DM, Lee BB (1994) The blue-ON opponent pathway in primate retina originates from a distinct bistratified ganglion cell type. Nature 367:731-735.

de Monasterio FM, Gouras P, Tolhurst DJ (1975) Concealed color-opponency in ganglion cells of the rhesus monkey retina. J Physiol (Lond) 251:251.

Derrington AM, Krauskopf J, Lemnie P (1984) Chromatic mechanisms in lateral geniculate nucleus of macaque. J Physiol (Lond) 357:241-265.

Doty RW, Glickstein M, Calvin WM (1966) Lamination of the lateral geniculate nucleus in the squirrel monkey. J Comp Neurol 127:335-340.

Ghosh KK, Goodchild AG, Sefton AE, Martin PR (1994) Morphological 
classification of ganglion cells in the retina of the common marmoset, Callithrix jacchus. Mustr Neurosei Soc Abstr 5:202.

Hendrickson AE, Wilson JR, Ogren MP (1978) The neuronanatomical organisation of pathways between the dorsal lateral geniculate nucleus and visual cortex in old world and new world primates. J Comp Neurol 182:123-136.

Hongyo T, Buzard GS, Calvert RJ, Weghorst CM (1993) 'Cold SSCP': a simple, rapid and non-radioactive method for optimized single-strand conformation polymorphism analyses. Nucleic Acids Res 21:3637-3642.

Hunt DM, Williams AJ, Bowmaker JK, Mollon JD (1993) Structure and evolution of polymorphic photopigment gene of the marmoset. Vision Res 33:147-154.

Jacobs GH (1983) Differences in spectral response properties of I GN cells in male and female squirrel monkeys. Vision Res 23:461-468.

Jacobs GH (1984) Within-species variations in visual capacity among squirrel monkeys (Saimiri sciureus): colour vision. Vision Res 24:1267 1277.

Jacobs GH, DeValois RL (1965) Chromatic opponent cells in squirrel monkey lateral geniculate nucleus. Nature 206:487-489.

Jacobs GH, Neitz J (1985) Color vision in squirrel monkeys: sex-related differences suggest the mode of inheritance. Vision Res 25:141-143.

Jacobs GH, Yolton RL (1970) Center-surround balance in receptive fields of cells in the lateral geniculate nucleus. Vision Res 10:1127-1144.

Jacobs GH, Neitz J, Crognale M (1987) Color vision polymorphism and its photopigment basis in a Callitrichid monkey (Saguinus fuscicollis). Vision Res 27:2089-2100.

Jacobs GH, Neitz J, Neitz M (1993) Genetic basis of polymorphism in the color vision of Platyrrhine monkeys. Vision Res 33:269-274.

Jordan G, Mollon JD (1993) A study of women heterozygous for colour deficiencies. Vision Res 33:1195-1508.

Judd DB (1951) Colorimetry and artificial daylight, in Technical Committee No. 7 Report of Secretariat United States Commission, International Commission on Illumination, Twelfth Session, Stockholm, pp 160.

Kaplan E, Shapley RM (1982) X and Y cells in the lateral geniculate nucleus of the macaque monkeys. J Physiol (Lond) 330:125-143.

Kaplan E, Shapley R (1984) The origin of the S (slow) potential in the mammalian lateral geniculate nucleus. Exp Brain Res 55:111-116.

Kaplan E, Shapley RM (1986) The primate retina contains two types of ganglion cells with high and low contrast sensitivity. Proc Natl Acad Sci USA 83:2755-2757.

Lee BB, Virsu V, Creutzfeldt OD (1983) Linear signal transmission from prepotentials to cells in the macaque lateral geniculate nucleus. Exp Brain Res 52:50-56.

Lee BB, Valberg A, Tigwell DA, Tryti J (1987) An account of responses of spectrally opponent neurons in macaque lateral geniculate nucleus to successive contrast. Proc R Soc Lond [Biol] 230:293-314.

Lee BB, Martin PR, Valberg A (1989a) Nonlinear summation of M- and $\mathrm{L}$-cone inputs to phasic retinal ganglion cells of the macaque. J Neurosci 9:1433-1442.

Lee BB, Martin PR, Valberg A (1989b) Sensitivity of macaque retinal ganglion cells to chromatic and luminance flicker. J Physiol (Lond) 414: 223-243.

Lee BB, Pokorny J, Smith VC, Martin PR, Valberg A (1990) Luminance and chromatic modulation sensitivity of macaque ganglion cells and human observers. J Opt Soc Am A 7:2223-2236.

Lee BB, Martin PR, Valberg A, Kremers J (1993) Physiological mechanisms underlying psychophysical sensitivity to combined luminance and chromatic modulation. J Opt Soc Am A 10:1403-1412.

Lee BB, Pokorny J, Smith VC, Kremers J (1994) Responses to pulses and sinusoids in macaque ganglion cells. Vision Res 34:3081-3096.

Leventhal AG, Ault SJ, Vitek DJ, Shou T (1989) Extrinsic determinants of retinal ganglion cell development in primates. J Comp Neurol 286: $170-189$.

Lindsey DT, Pokorny J, Smith VC (1986) Phase-dependent sensitivity to heterochromatic flicker. J Opt Soc Am A 3:921-927.

Malpeli JG, Baker FH (1975) The representation of the visual field in the lateral geniculate nucleus of Macaca mulatta. J Comp Neurol 161:569594.

Martin PR, Grunert U, Lee BB, Wilder H (1995) Retinal ganglion cell topography in di- and trichromatic marmoset monkeys (Callithrix jacchus). Inv Ophthalmol Visual Sci 36:S4.

McCormick DA, Feeser HR (1990) Functional implications of burst firing and single spike activity in lateral geniculate relay neurons. Neuroscience 37:103-113.

Nagy AL, MacLeod DA, Heynemann NE, Eisner A (1981) Four cone pigments in women heterozygous for color deficiency. J Opt Soc Am $71: 719-722$.

Naka KI, Rushton WA (1966) S-potentials from colour units in the retina of fish (Cyprinidae). J Physiol (Lond) 185:536-555.

Padmos P, van Norren D (1975) Cone systems interaction in single neurons of the lateral geniculate nucleus of the macaque. Vision Res 15:617619.

Purpura K, Kaplan E, Shapley RM (1988) Background light and the contrast gain of primate $\mathrm{P}$ and $\mathrm{M}$ retinal ganglion cells. Proc Natl Acad Sci USA 85:4534 4537.

Shapley R, Perry VH (1986) Cat and monkey retinal ganglion cells and their visual functional roles. Trends Neurosci 9:229-235.

Shapley RM, Victor JD (1978) The effect of contrast on the transfer properties of cat retinal ganglion cells. J Physiol (Lond) 285:275-298.

Sherman SM, Wilson JR, Kaas JH, Webb SV (1976) X- and Y-cells in the dorsal lateral geniculate nucleus of the owl monkey (Aotus trivergatus). Science 192:475-477.

Smith VC, Lee BB, Pokorny J, Martin PR, Valberg A (1992) Responses of macaque ganglion cells to the relative phase of heterochromatically modulated lights. J Physiol (Lond) 458:191-221.

Spat7. WR (1978) The retino-geniculo-cortical pathway in Callithrix. I. Intraspecific variations in the lamination pattern of the lateral geniculate nucleus. Exp Brain Res 33:551-563.

Stone J, Johnstone E (1981) The topography of primate retina: a study of the human, bushbaby and new- and old-world monkeys. J Comp Neurol 196:205-223.

Swanson WH, Ueno T, Snnith VC, Pokony J (1987) Temporal modlulation sensitivity and pulse detection thresholds for chromatic and luminance perturbations. J Opt Soc Am A 4:1992-2005.

Tovee MJ, Bowmaker JK, Mollon JD (1992) The relationship between cone pigments and behavioral sensitivity in a new world monkey ( $\mathrm{Cal}$ lithrix jacchus). Vision Res 32:867-878.

Troilo D, Howland HC, Judge SJ (1993) Visual optics and retinal cone topography in the common marmoset (Callithrix jacchus). Vision Res 33:1301-1310.

Troy JB, Oh JK, Enroth-Cugell C (1993) Effect of ambient illumination on the spatial properties of center and surround of Y-cell receptive fields. Visual Neurosci 10:753-761.

Valberg A, Seim T (1991) On the physiological basis of higher color metrics. In: From pigments to perception (Valberg A, Lee BB, eds), pp 425-436. New York: Plenum.

Virsu V, Lee BB (1983) Light adaptation in cells of macaque lateral geniculate nucleus and its relation to human light adaptation. $\mathbf{J}$ Neurophysiol 50:864-877.

Virsu V, Lee BB, Creutzfeldt OD (1987) Mesopic spectral responses and the Purkinje shift of macaque lateral geniculate cells. Vision Res 27: 191-200.

Wässle H, Boycott BB (1991) Functional architecture of the mammalian retina. Physiol Rev 71:447-480.

Westheimer G (1966) The Maxwellian view. Vision Res 6:669-682.

Wiesel T, Hubel DH (1966) Spatial and chromatic interactions in the lateral geniculate body of the rhesus monkey. J Neurophysiol 29:1115-1156.

Williams AJ, Hunt DM, Bowmaker JK, Mollon JD (1992) The polymorphic photopigments of the marmoset: spectral tuning and genetic basis. EMBO J 6:2039-2045.

Wong-Riley MTT (1972) Neuronal and synaptic organization of the normal lateral geniculate nucleus of the squirrel monkey, Saimiri sciureus. J Comp Neurol 144:25-60.

Yeh T, Lee BB, Kremers J, Martin PR (1994) Responses of marmoset PCand $\mathrm{MC}$-cells to luminance and chromatic stimuli. Inv Ophthalmol Visual Sci 35:1975.

Yeh T, Lee BB, Kremers J (1995) The temporal response of ganglion cells of the macaque retina to cone-specific modulation. J Opt Soc Am A 12: $456-464$. 